\title{
Buckling behaviour of thin-walled laminated composite beams having open and closed sections subjected to axial and end moment loading
}

\author{
Arash Asadi ${ }^{1}$, Abdul Hamid Sheikh ${ }^{1}$ and Ole Thybo Thomsen ${ }^{2}$ \\ ${ }^{1}$ School of Civil, Environmental and Mining Engineering, the University of Adelaide, Adelaide, Australia \\ ${ }^{2}$ Faculty of Engineering and Physical Sciences, University of Southampton, Highfield, Southampton, United \\ Kingdom
}

Keywords: Thin-walled composite beams, buckling, shear deformation, warping, finite element modelling

\begin{abstract}
An efficient modelling technique based on one dimensional (1D) beam finite element analysis for buckling of thin-walled laminated composite beams having open/closed sections is proposed. The formulation derived has sufficient generality for accommodating arbitrary stacking sequences of the individual beam section walls, and includes all possible couplings between axial, shear, bending and torsional modes of deformation. The effects of transverse shear deformation of the section walls and out-of-plane warping of the beam section are considered where provision exists to restrain or allow warping deformation. The incorporation of shear deformation leads to a problem in the finite element implementation of the proposed beam kinematics, but this is successfully addressed adopting a novel modelling concept. Numerical results obtained for the sample cases of open sections I beams and closed section box beams are presented. The numerical results are benchmarked/compared to data available in open literature, and it is shown that the proposed model performs very well. Finally, a study of the effect of axial and end moment loading, acting alone or in combination, on the buckling response of thin-walled composite beams is presented.
\end{abstract}

\section{INTRODUCTION}

\subsection{Background}

The use of long beam like structural components having a thin-walled construction is common in many real-life engineering products such as wind turbine blades, helicopter rotor blades, aero-structures, ship masts and many other civil engineering applications such as composite beams, columns and reinforcement. In recent years, laminated fibre reinforced composite materials (hereinafter referred to as composites) have gained widespread acceptance and usage as structural materials in various engineering products including the above mentioned structural applications. The rationale is that composites helps to enhance the structural performance significantly due to high specific strength and stiffness in addition to high fatigue resistance and durability. The use of composite structural elements utilising multi-layered composite laminates with arbitrary fibre orientations of the individual layers (plies) provide a high degree of flexibility in tailoring the structural performance, but this can lead to complexities in their behaviour due to couplings between different modes of deformation. Thus, the use of composites introduces additional challenges in the modelling of composite structures of thin-walled construction, which is already inherently complex for thin-walled structures made from isotropic materials due to warping deformation and other characteristic behaviours. In principle, the load-response behaviour of the thin-walled construction composite structural elements of open or closed cross section may be analysed using a 3D modelling strategy based on solid or shell finite elements (FE), but this modelling technique is unfeasible in many cases due to high computational cost and time. To address 
this problem previous research available in open literature has proposed to develop alternative modelling techniques, preferably based on 1D FE beam elements, which leads to more efficient and affordable techniques for modelling [e.g. 1-9]. However, a real and significant challenge in developing such reduced order 1D FE models is the inclusion of all relevant physical coupling effects in the condensed (1D) formulation for thin-walled composite beams.

The relevant previous research can be broadly divided into two groups based on the approaches used for determining the constitutive matrix of the beam element. The first approach is based on 'analytical techniques', while the second alternative utilises a twodimensional (2D) cross-sectional analysis based on a 2D finite element model for calculating the cross-sectional matrices. Hodges et al. $[3,10,11]$ have contributed significantly toward the development of the second approach, which has significant merit in terms of generality, but the 2D finite element analysis needed for the evaluation of cross-sectional stiffness coefficients is a major task. This was experienced and documented in a recent study [12], which is based on a similar approach. On the other hand, the first option (analytical approach), like that presented in Ref. [6], adopted in this paper does not require 2D finite element analysis, nor does it involve the complex mathematical operations involved with the second approach.

\subsection{Review of analytical approaches}

Vo and Lee et al. studied the behaviour of thin-walled composite beams having open [e.g. 13] and closed [e.g. 14] sections, including buckling analysis. It is observed that their analyses are mostly based on classical lamination theory, thus neglecting the effect of shear deformation of the composite laminated section walls. However, composite laminates are generally weak in transverse shear due to their low shear stiffness and strength relative to the extensional rigidity and strength. Thus, it is important to incorporate the effect of shear deformation to ensure reliable predictive capability for all relevant loading scenarios. In order to address this issue, Vo and Lee [15] incorporated the effect of shear deformation, but the treatment adopted for the finite element implementation of torsional deformations is not promising. They [15] simply extended the concept used for the incorporation of transverse shear deformation in a typical isoparametric $\mathrm{FE}$ formulation to express the torsional deformation by introducing an additional parameter. This parameter is analogous to the transverse shear strain but, unfortunately, it does not have any real physical representation. Moreover, the formulation faced the difficulty of breaking down the torsional moment into three components as they attempted to express the beam response behaviour of these beams in terms of stress resultants. With this treatment for the torsion, they [15] succeeded to derive their beam element using an isoparametric formulation for all deformation modes. The element has 3 nodes thus providing a quadratic interpolation of all (seven) field variables using Lagrangian interpolation functions giving seven degrees of freedom at each node.

Kim et al. [16-18] also considered the effect of shear deformations following the concept introduced by Vo and Lee [15] and encountered similar difficulties. Thus, for the finite element implementation of the beam theory, an isoparametric formulation for all field variables to develop a beam element having $C^{0}$ continuous deformations was adopted. The well-known shear locking problem is typically faced in isoparametric elements as this formulation use the same interpolation functions for all field variables. A simple solution of this problem is the application of a reduced integration technique, as adopted by Kim et al. [16-18], but that may lead to spurious zero energy modes for some cases in addition to stress oscillations within the element. Moreover, the reduced integration will affect the evaluation of the stiffness corresponding to other modes of deformation, including axial and torsion modes and their couplings. Furthermore, it is also difficult to apply a selective reduced 
integration scheme in this coupled problem. However, Kim et al. [e.g. 16-18] have contributed significantly in this area through investigating various aspects of thin-walled section composite beams.

Piovan and Cortinez [19] developed a shear deformable beam element following a different approach which seems to be interesting. The beam element has also incorporated the effects of warping. In order to avoid shear locking problem, the implementation of shear deformation has been achieved by defining transverse displacement and its derivatives as done in classical beam model, but an additional term been added to the expression for the derivative of transverse displacement. This additional term contributes to the shear deformation, but it is a function of material property and geometry of the element which need to be calculated for individual cases separately. Also, this term seems to be constant over the beam length. The same treatment has also been applied to the torsional deformation of the beam taking torsional rotation and its derivative accompanied with a similar function.

Ascione et al. [20] proposed another interesting approach where different plate elements forming the beam section are taken separately as beams and they are connected at their longitudinal edges using spring elements. This approach helped to accommodate different features including shear deformation, but this model needs more unknowns as it will have multiple nodes at any cross-section.

The formulations presented by both these groups [14,16] are consistent when the contribution of shear deformation is neglected. For this case, the Lagrangian interpolation functions are only used for the axial deformation, whereas other deformation modes, i.e. torsion and bending (bi-axial), are interpolated with Hermitian interpolation functions. Thus, these elements provide $\mathrm{C}^{0}$ continuity ( 1 degree of freedom at each node - field variable only) for the axial displacement, and $\mathrm{C}^{1}$ continuity ( 2 degrees of freedom at each node - field variable and its derivative) for the other modes of deformation.

\subsection{Proposed Model}

The aim of this this study is to develop a consistent formulation that includes the effect of shear deformation as composite materials are compliant/weak in shear as mentioned above. In this formulation, the issues associated with the existing modelling approaches e.g. $[15,18]$, discussed in detail above, will be overcome by introducing an alternative approach. The proposed formulation will be applied to study the buckling characteristics of thin-walled composite beams with open or closed cross sections subjected to axial forces, end moments and combinations of these. The different modes of deformation and their coupling included in the formulation include: axial, torsional, bi-axial bending, bi-axial shear as well as warping (for torsion) deformation. The cross-sectional stiffness property matrices are derived in closed-form for both open and closed beam cross sections, including the assumption of both plane stress and plain strain conditions at the lamina level. Once the cross-sectional matrices of these thin-walled composite beams are derived, the remaining part of the analysis is the formulation and solution of the 1D beam problem, which in this study is achieved by adopting a finite element approximation.

Numerical examples of thin-walled composite beams having different cross sections, material configurations, boundary conditions and other features have been analysed by the proposed model, and the results obtained are presented in terms of predicted critical buckling loads (axial and end moment loads) and buckling mode-shapes. A significant amount of the numerical predictions have been compared and benchmarked against results available in 
literature, and it is demonstrated that the proposed modelling approach provides a very close match with other model predictions, and that it generally performs very well. New numerical results are also presented for a number of problems that may be beneficial to future research efforts in this area.

\section{MODEL FORMULATION}

\subsection{Finite element formulation - basic concepts}

The conventional treatment adopted for incorporating transverse shear deformation in an isoparametric finite element context requires a $\mathrm{C}^{0}$ continuous formulation, whilst the warping displacement produced by torsion requires a $\mathrm{C}^{1}$ continuous formulation for the twisting rotation. The $\mathrm{C}^{1}$ formulation for the torsional deformation is conveniently achieved in this study by using cubic Hermitian interpolation functions, including the angle of twist and its derivative at the two end nodes of the proposed beam element, see Fig. 1. Alternatively, if the $\mathrm{C}^{0}$ continuous formulation is adopted for the transverse shear deformation, this will require adoption of a reduced integration technique, but its implementation is problematic in the present coupled problem as discussed above. This is a crucial issue, which in this study is addressed adopting the approach proposed by Sheikh [22], which eliminates the need for do reduced integration.

Adopting the above, a 3 noded beam element as shown in Fig.1 has been developed, where the end nodes have 7 degrees of freedom (3 displacements, 3 rotations and the derivative of the torsional rotation), and the middle node has 5 degrees of freedom (3 displacements, 2 bending rotations). It should be noted that quadratic Lagrangian interpolation functions are used to model the axial deformation taking 1 degrees of freedom at each node. A computer code was written in MATLAB for the implementation of the formulation.

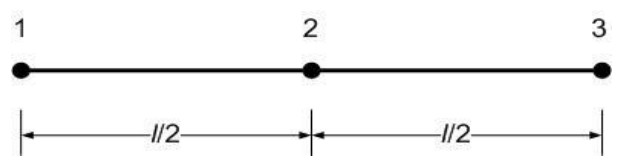

Fig. 1: Schematic of beam finite element

\subsection{Kinematics of the beam deformations}

Fig. 2 shows part of the cross section of a laminated beam wall segment along with global and local coordinate systems and their corresponding displacement components, which form the basis for the development of the proposed formulation. The curved geometry of the section wall is shown to represent a generic scenario, but the section walls can also be of straight geometry. 


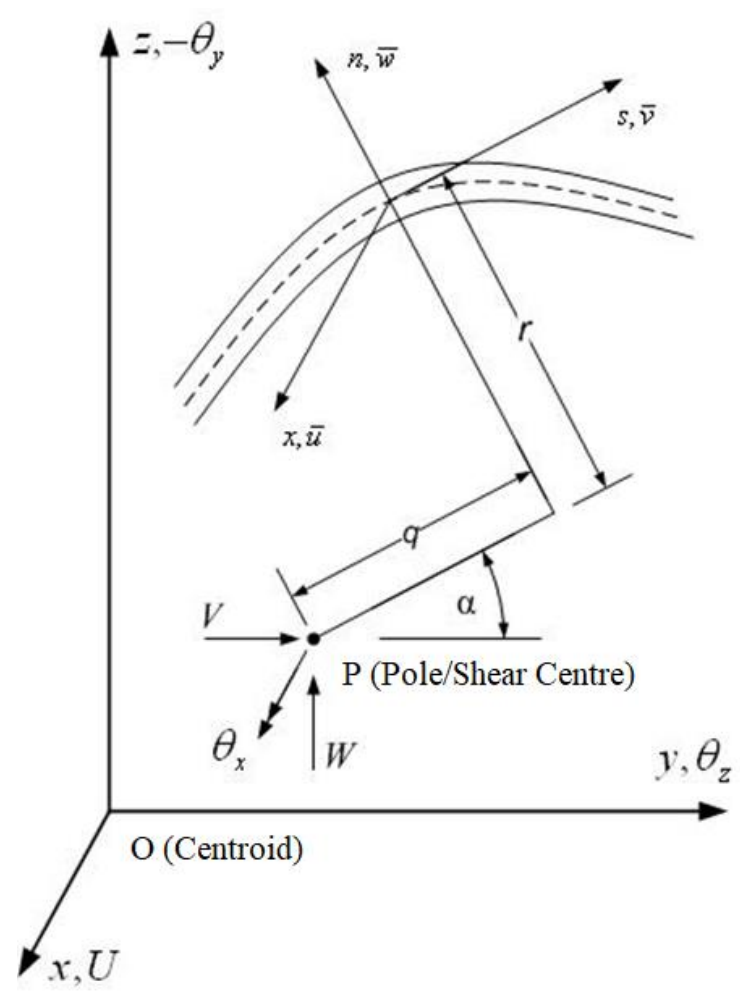

Fig. 2: Cross section of a beam section wall segment with local and global coordinate system and corresponding displacement components

In Fig. $2 x-y-z$ axes define the global Cartesian coordinate system, where $x$ is along the beam axis, passing through the centroid of the complete beam cross section, and $y, z$ define the beam cross section coordinates. The other axes are the local orthogonal coordinate system $x-s-n$, defined at the mid-plane of a laminated section wall, where $n$ is normal to the shell (wall) mid-plane, $s$ is the circumference coordinate, and $x$ is parallel to global $x$ coordinate axis. The displacement components at the mid-plane of the shell wall in the local coordinate system $(x-s-n)$ can be expressed in terms of the global displacements of the beam (Fig. 2) in the form [22]:

$$
\begin{aligned}
& \bar{u}=U+y \theta_{y}+z \theta_{z}+\phi \theta_{x}^{\prime}, \\
& \bar{v}=V \cos \alpha+W \sin \alpha-r(s) \theta_{x}, \\
& \bar{w}=-V \sin \alpha+W \cos \alpha+q(s) \theta_{x},
\end{aligned}
$$

where $\theta_{y}, \theta_{z}$ are bending rotations (including shear deformations) of the beam cross section relative to the along $y$ and $z$ axes, respectively, $\theta_{x}$ is the torsional rotation of the beam cross section relative to the $x$ axis, and $\varphi$ is the warping function. $U, V$ and $W$ are the displacement components in the global $x, y$ and $z$ coordinate directions. Defining $\Psi_{y}, \Psi_{z}$ as cross-sectional rotations due to shear deformations of the beam section about the $y$ and $z$ axes, the bending rotations can be expressed as $\theta_{y}=-V^{\prime}+\Psi_{y}$ and $\theta_{z}=-W^{\prime}+\Psi_{z}$, respectively, and $V^{\prime}, W^{\prime}$ and $\theta_{x}^{\prime}$ are the derivatives of $V, W$ and $\theta_{x}$ with respect to $x$.

Although the effects of warping displacement in beams having closed cross sections is generally not as significant as for beams with open cross section [21], the contribution of 
warping displacements is incorporated for both types of cross sections to deliver a generic formulation.

The displacement at any point of the shell wall located at a distance $n$ from the shell wall mid-plane can be expressed in terms of the bending and transverse shear deformations of the wall as:

$$
\begin{aligned}
& u=\bar{u}+n\left(-\frac{\partial \bar{w}}{\partial x}+\psi_{x n}\right), \\
& v=\bar{v}+n\left(-\frac{\partial \bar{w}}{\partial s}+\psi_{s n}\right), \\
& w=\bar{w}
\end{aligned}
$$

where $\psi_{x n}$ and $\psi_{s n}$ are rotations of the shell wall sections due to shear deformations about $s$ and $x$, respectively. Now, $\psi_{x n}$ can be expressed in terms of the corresponding global cross section rotations $\left(\Psi_{y}, \Psi_{z}\right)$ as $\psi_{x n}=-\Psi_{y} \sin \alpha+\Psi_{z} \cos \alpha$, whereas $\psi_{s n}=0$ based on the restrictive assumption that the overall shape of the beam cross section will not be altered during the deformation of the beam.

Substituting the above expressions for $\psi_{x n}$ and $\psi_{s n}$ as well as Eq. (1) into Eq. (2), the displacements at any point within the shell wall along its local coordinate system $(x-s-n)$ can be expressed in terms of the global displacement components of the $1 \mathrm{D}$ beam as follows:

$$
\begin{aligned}
& u=U+(y-n \sin \alpha) \theta_{y}+(z+n \cos \alpha) \theta_{z}+(\phi-n q(s)) \theta_{x}^{\prime}, \\
& v=V \cos \alpha+W \sin \alpha-(r(s)+n) \theta_{x}, \\
& w=-V \sin \alpha+W \cos \alpha+q(s) \theta_{x}
\end{aligned}
$$

\subsection{Energy systems of the beam}

The potential energy ( $\Pi$ ) of a beam undergoing buckling caused by an external forces can be expressed in terms of the strain energy $(U)$ and the work done by external forces $\left(W_{e}\right)$ as:

$$
\Pi=U-W_{e}
$$

Now the strain energy appeared in the above equation can be expressed in terms of stress $\{\sigma\}$ and strain $\{\varepsilon\}$ vectors of the shell walls expressed in their local axis system $(x-s-n)$ as:

$$
U=\frac{1}{2} \int\{\varepsilon\}^{T}\{\sigma\} d v
$$

The relationship between the above stress and strain vectors for a ply of the laminated shell wall having any orientation can be expressed using its constitutive matrix $[\bar{Q}]$ following 'classical lamination theory' (CLT) as described in texts on mechanics of composite materials [4] as: 


$$
\{\sigma\}=\left\{\begin{array}{c}
\sigma_{x} \\
\sigma_{s} \\
\sigma_{x s} \\
\sigma_{x n} \\
\sigma_{s n}
\end{array}\right\}=\left[\begin{array}{ccccc}
\bar{Q}_{11} & \bar{Q}_{12} & \bar{Q}_{16} & 0 & 0 \\
\bar{Q}_{21} & \bar{Q}_{22} & \bar{Q}_{26} & 0 & 0 \\
\bar{Q}_{61} & \bar{Q}_{62} & \bar{Q}_{66} & 0 & 0 \\
0 & 0 & 0 & \bar{Q}_{55} & \bar{Q}_{54} \\
0 & 0 & 0 & \bar{Q}_{45} & \bar{Q}_{44}
\end{array}\right]\left\{\begin{array}{c}
\varepsilon_{x} \\
\varepsilon_{s} \\
\varepsilon_{x s} \\
\varepsilon_{x n} \\
\varepsilon_{s n}
\end{array}\right\}=[\bar{Q}]\{\varepsilon\}
$$

The above equation is written in terms of all five stress and strain components typically occurring in a shell element, but some of these components will not be present in the present problem due to the restrictive assumption adopted that the beam cross section will not change shape during deformation. Thus, there will be no bending and shear deformations in the $s-n$ plane, which leads to $\psi_{n s}=0$ and $\sigma_{s}=0$ (usually defined as plane stress condition) or $\varepsilon_{s}=0$ (plane strain condition). By incorporating this the above equation reduces to:

$$
\{\sigma\}=\left\{\begin{array}{c}
\sigma_{x} \\
\sigma_{x s} \\
\sigma_{x n}
\end{array}\right\}=\left[\begin{array}{ccc}
\tilde{Q}_{11} & \tilde{Q}_{16} & 0 \\
\tilde{Q}_{61} & \tilde{Q}_{66} & 0 \\
0 & 0 & \tilde{Q}_{55}
\end{array}\right]\left\{\begin{array}{l}
\varepsilon_{x} \\
\varepsilon_{x s} \\
\varepsilon_{x n}
\end{array}\right\}=[\tilde{Q}]\{\varepsilon\}
$$

where $\tilde{Q}_{11}=\bar{Q}_{11}, \tilde{Q}_{16}=\bar{Q}_{16}, \tilde{Q}_{66}=\bar{Q}_{66}$ and $\tilde{Q}_{55}=\bar{Q}_{55}$ for plane strain condition $\left(\varepsilon_{s}=0\right)$; and $\tilde{Q}_{11}=\bar{Q}_{11}-\bar{Q}_{12} \bar{Q}_{12} / \bar{Q}_{22}, \quad \tilde{Q}_{16}=\bar{Q}_{16}-\bar{Q}_{12} \bar{Q}_{26} / \bar{Q}_{22}, \tilde{Q}_{66}=\bar{Q}_{66}-\bar{Q}_{16} \bar{Q}_{16} / \bar{Q}_{22}$ and $\tilde{Q}_{55}=\bar{Q}_{55}$ for plane stress $\left(\sigma_{s}=0\right)$ condition.

The substitution of the expressions for the local displacement components, at any point of the shell wall in terms of the global displacement components (Eq. 3), into the reduced strain vector (Eq. (7)), leads to:

$$
\{\varepsilon\}=\left\{\begin{array}{c}
\partial u / \partial x \\
\partial u / \partial s+\partial v / \partial x \\
\psi_{x n}
\end{array}\right\}=\left\{\begin{array}{c}
U^{\prime}+(y-n \sin \alpha) \theta_{y}^{\prime}+(z+n \cos \alpha) \theta_{z}^{\prime}+(\phi-n q) \theta_{x}^{\prime \prime} \\
\Psi_{y} \cos \alpha+\Psi_{z} \sin \alpha-(2 n+r-\partial \phi / \partial s) \theta_{x}^{\prime} \\
-\Psi_{y} \sin \alpha+\Psi_{z} \cos \alpha
\end{array}\right\}
$$

The local strain vector can now be decoupled in terms of the cross section stiffness matrix $([H])$ and strain vector of the beam $(\{\overline{\boldsymbol{\varepsilon}}\})$ which contains global displacement parameters for $1 \mathrm{D}$ beam as :

$$
\{\boldsymbol{\varepsilon}\}=[H]\{\overline{\boldsymbol{\varepsilon}}\}
$$

where

$$
\begin{aligned}
& \{\bar{\varepsilon}\}=\left\{\begin{array}{lllllll}
U^{\prime} & \theta_{y}^{\prime} & \theta_{z}^{\prime} & \theta_{x}^{\prime \prime} & \theta_{x}^{\prime} & V^{\prime}+\theta_{y} & W^{\prime}+\theta_{z}
\end{array}\right\}^{T} \\
& {[H]=\left[\begin{array}{ccccccc}
1 & y-n \sin \alpha & z+n \cos \alpha & \phi-n q & 0 & 0 & 0 \\
0 & 0 & 0 & 0 & -\left(2 n+r-\phi_{, s}\right) & \cos \alpha & -\sin \alpha \\
0 & 0 & 0 & 0 & 0 & \sin \alpha & \cos \alpha
\end{array}\right]}
\end{aligned}
$$


By substitution of Eqs. (7-9) into Eq. (5), the strain energy of the system can be expressed as:

$$
U=\frac{1}{2} \int\{\varepsilon\}^{T}\{\sigma\} d v=\frac{1}{2} \int\{\bar{\varepsilon}\}^{T}[H]^{T}[\tilde{Q}][H]\{\bar{\varepsilon}\} d n d s d x=\frac{1}{2} \int\{\bar{\varepsilon}\}^{T}[D]\{\bar{\varepsilon}\} d x
$$

where

$$
[D]=\int\left(\int[H]^{T}[\tilde{Q}][H] d n\right) d s=\int[C] d s
$$

All individual elements of the matrix $[C]$ are derived explicitly in closed form. Similarly, all elements of the cross sectional stiffness matrix $[D]$ are derived specifically and in closed form for open I section and closed box section profiles having generic geometric configurations, as depicted in Fig. 3. This includes general specification of cross section dimensions, and arbitrary lay-up (stacking sequence) of the cross section walls in terms of choice of material, number of plies, and ply orientations. The explicit expressions for the components of $[C]$ and $[D]$ are derived in a previous article by the authors [23].

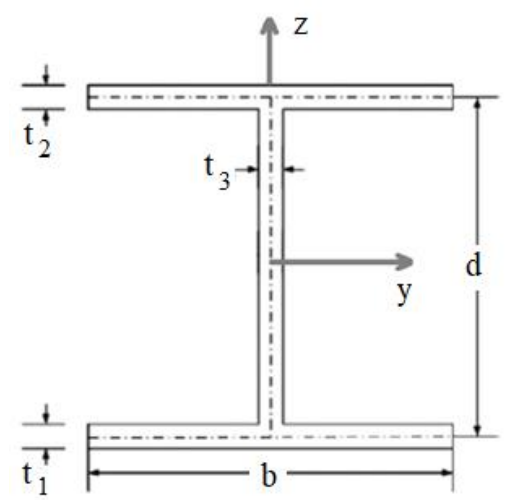

(a)

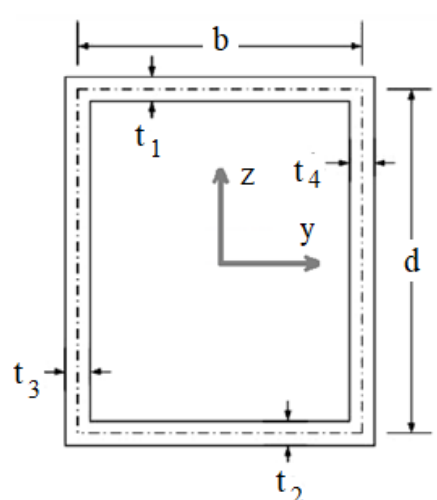

(b)

Fig. 3: Thin-walled beam having open and closed section

For the purpose of this study the warping function $\varphi$ used in the above equations are taken as:

$$
\phi=\int r d s-2 A_{c} \delta_{s} / \delta
$$

where $\delta_{s}=\int \frac{d s}{\tilde{Q}_{66}}, \quad \delta=\oint \frac{d s}{\tilde{Q}_{66}}$. For a closed beam cross section profile $A_{c}$ is the crosssectional area enclosed by the wall mid-plane line/contour. For an open section profile, the warping function may be simply obtained by dropping the second term associated with secondary warping, thus giving $\phi=\int r d s$.

The external forces considered in this study, which will be causing the buckling of the thin-walled composite beams are axial force $\left(P_{0}\right)$ and end moment $\left(M_{0}\right)$ loading. Both these forces induce only one stress component, the axial stress $\left(\sigma_{x}\right)$, which can be expressed in simple form and used to formulate the problem conveniently, i.e.: 


$$
\sigma_{x}=\frac{P_{\circ}}{A}+\frac{M_{0}^{y}}{I_{y}} z
$$

where $A$ and $I_{y}$ are cross-sectional area and moment of inertia of the beam cross sectional area. It should be noted that the above equation will give a stress that can be defined as an equivalent stress. The aim here to estimate this stress in a simple way without affecting the results significantly rather than undertaking a detailed analysis for predicting the stress distribution over the individual layers precisely. The work done $\left(W_{e}\right)$ by the external forces $P_{0}$ and $M_{0}$ can be expressed as:

$$
W_{e}=\frac{1}{2} \int_{V} \sigma_{x}\left(v^{\prime 2}+w^{\prime 2}\right) d v=\frac{1}{2} \int_{V}\left\{\begin{array}{cc}
v^{\prime} & w^{\prime}
\end{array}\right\} \sigma_{x}\left\{\begin{array}{l}
v^{\prime} \\
w^{\prime}
\end{array}\right\} d v=\frac{1}{2} \int_{V}\left\{\varepsilon_{g}\right\}^{T} \sigma_{x}\left\{\varepsilon_{g}\right\} d v
$$

Using Eq. (3), the geometric strain vector $\left\{\boldsymbol{\varepsilon}_{g}\right\}$ in the above equation can be written as

$$
\left\{\varepsilon_{g}\right\}=\left\{\begin{array}{c}
v^{\prime} \\
w^{\prime}
\end{array}\right\}=\left[\begin{array}{ccc}
\cos \alpha & \sin \alpha & -(r+n) \\
-\sin \alpha & \cos \alpha & q
\end{array}\right]\left\{\begin{array}{c}
V^{\prime} \\
W^{\prime} \\
\theta_{x}^{\prime}
\end{array}\right\}=\left[H_{g}\right]\left\{\bar{\varepsilon}_{g}\right\} .
$$

Eqs. (14) and (16) may be substituted into Eq. (15) leading to:

$$
\begin{aligned}
& W_{e}=\frac{P_{0}}{2 A} \int_{V}\left\{\varepsilon_{g}\right\}^{T}\left\{\varepsilon_{g}\right\} d v+\frac{M_{0}}{2 I_{y}} \int_{L}\left\{\varepsilon_{g}\right\}^{T} z\left\{\varepsilon_{g}\right\} d v \\
& =\frac{P_{0}}{2 A} \int_{L}\left\{\bar{\varepsilon}_{g}\right\}^{T}\left[F_{g}^{P}\right]\left\{\bar{\varepsilon}_{g}\right\} d x+\frac{M_{0}}{2 I_{y}} \int_{L}\left\{\bar{\varepsilon}_{g}\right\}^{T}\left[F_{g}^{M}\right]\left\{\bar{\varepsilon}_{g}\right\} d x
\end{aligned}
$$

where

$$
\begin{aligned}
& {\left[F_{g}^{P}\right]=\int_{A}\left[H_{g}\right]^{T}\left[H_{g}\right] d s d n=\int\left(\int\left[H_{g}\right]^{T}\left[H_{g}\right] d n\right) d s=\int\left(\left[C_{g}^{P}\right]\right) d s} \\
& {\left[F_{g}^{M}\right]=\int_{A}\left[H_{g}\right]^{T} z\left[H_{g}\right] d s d n}
\end{aligned}
$$

The individual elements of the matrices $\left[C_{g}^{P}\right]$ are derived explicitly and provided in Appendix A. Also, all elements of the matrices $\left[F_{g}^{P}\right]$ and $\left[F_{g}^{M}\right]$ are derived for the considered generic I (open) and box (closed) beam sections and given in Appendix B.

\subsection{Finite element formulation}

For the 1D finite element implementation of the thin-walled beam theory based on the energy expressions presented in the previous section, quadratic Lagrangian interpolation functions are used for the axial deformation, while cubic Hermitian interpolation functions are used for the torsional deformation. This ensures the desired $\mathrm{C}^{1}$ continuity of the torsional rotation $\left(\theta_{x}\right)$ as the strain vector (Eq. 8) contains second derivative of $\theta_{x}$. As mentioned earlier, the bending deformations along with the shear deformations are treated in a different manner following the approach introduced in [21] to eliminate the difficulties faced by other 
existing formulations [13-15], [16-18]. According to [21], the cross-sectional rotations $\Psi_{y}$ and $\Psi_{z}$ due to shear deformations are adopted as field variables instead of $\theta_{y}$ and $\theta_{z}$ in addition to the bending displacements $V$ and $W$. adopting a linear approximation of $\Psi_{y}, \Psi_{z}$, and a cubic approximation of $V$ and $W$, these field variables $\left(V, W, \Psi_{y}\right.$ and $\left.\Psi_{z}\right)$ along with the remaining two field variables ( $U$ and $\theta_{x}$ ) can be expressed in the form:

$$
\begin{aligned}
& U=a_{1}+a_{2} x+a_{3} x^{2} \\
& V=a_{4}+a_{5} x+a_{6} x^{2}+a_{7} x^{3} \\
& W=a_{8}+a_{9} x+a_{10} x^{2}+a_{11} x^{3} \\
& \Psi_{y}=a_{12}+a_{13} x \\
& \Psi_{z}=a_{14}+a_{15} x \\
& \theta_{x}=a_{16}+a_{17} x+a_{18} x^{2}+a_{19} x^{3}
\end{aligned}
$$

It should be noted that $\Psi_{y}$ and $\Psi_{z}$ are defined as field variables, but they are not used as nodal degrees of freedom in the finite element formulation. The corresponding nodal degrees of freedom correspond to $\theta_{y}$ and $\theta_{z}$ which can be expressed in the following form $\theta_{y}$ and $\theta_{z}$ by invoking the above Eqs. (19):

$$
\begin{aligned}
& \theta_{y}=\Psi_{y}-V^{\prime}=a_{12}+a_{13} x-a_{5}-2 a_{6} x-3 a_{7} x^{2} \\
& \theta_{z}=\Psi_{z}-W^{\prime}=a_{14}+a_{15} x-a_{9}-2 a_{10} x-3 a_{11} x^{2}
\end{aligned}
$$

The unknown constants $\left(a_{1}, a_{2}, a_{3} \ldots . . . a_{19}\right)$ appearing in Eqs. (19) can be replaced in terms of the nodal displacement vector $\{\delta\}$ by substitution of $U, V, W$ (from Eqs. 19), $\boldsymbol{\theta}_{y}$ and $\boldsymbol{\theta}_{z}$ (from Eq. (20)) at all three nodes of the beam element (see Fig. 1), and $\theta_{x}$ (from Eqs. (19)) and its derivative $\theta_{x}^{\prime}\left(=a_{17}+2 a_{18} x+3 a_{19} x^{2}\right)$ at the two end nodes, thus giving:

$$
\{\delta\}=[R]\{a\} \text { or }\{a\}=[R]^{-1}\{\delta\}
$$

where $\{a\}^{T}=\left[\begin{array}{lllll}a_{1} & a_{2} & a_{3} & \cdots & a_{19}\end{array}\right],[R]$ consists of the coordinates ( $x$ values) of the 3 nodes and

$$
\{\delta\}=\left\{\begin{array}{lllllllllllllllllll}
U_{1} & V_{1} & W_{1} & \theta_{x 1} & \theta_{y 1} & \theta_{z 1} & \theta_{x 1}^{\prime} & U_{2} & V_{2} & W_{2} & \theta_{y 2} & \theta_{z 2} & U_{3} & V_{3} & W_{3} & \theta_{x 3} & \theta_{y 3} & \theta_{z 3} & \theta_{x 3}^{\prime}
\end{array}\right\}^{T} .
$$

Using Eqs. (19-21), the strain vector of the beam $\{\overline{\boldsymbol{\varepsilon}}\}$ as appearing in Eq. (9) can be expressed in terms of the nodal displacement vector $\{\delta\}$ as:

$$
\begin{aligned}
& \{\bar{\varepsilon}\}=\left\{\begin{array}{lllllll}
U^{\prime} & \theta_{y}^{\prime} & \theta_{z}^{\prime} & \theta_{x}^{\prime \prime} & \theta_{x}^{\prime} & V^{\prime}+\theta_{y} & W^{\prime}+\theta_{z}
\end{array}\right\}^{T} \\
& =[S(x)]\{a\}=[S(x)][R]^{-1}\{\delta\}=[B]\{\delta\}
\end{aligned}
$$


The above equation can be substituted into Eq. (11) and it is rewritten to get the stiffness matrix $[K]$ of the beam element as

$$
U=\frac{1}{2} \int\{\bar{\varepsilon}\}^{T}[D]\{\bar{\varepsilon}\} d x=\frac{1}{2}\{\delta\}^{T} \int[B]^{T}[D][B] d x\{\delta\}=\frac{1}{2}\{\delta\}^{T}[k]\{\delta\}
$$

Again Eqs. (19 - 21) can be substituted into the vector $\left\{\bar{\varepsilon}_{g}\right\}$ as found in Eq. (16) and it can further be expressed in terms of $\{\delta\}$ as:

$$
\left\{\bar{\varepsilon}_{g}\right\}=\left[\begin{array}{lll}
V^{\prime} & W^{\prime} & \theta_{x}^{\prime}
\end{array}\right]^{T}=\left[S_{g}(x)\right]\{a\}=\left[S_{g}(x)\right][R]^{-1}\{\delta\}=\left[B_{g}\right]\{\delta\} .
$$

The above equation is substituted into Eq. (17) and rewritten in the form:

$$
\begin{gathered}
W_{e}=\frac{P_{0}}{2 A} \int_{L}\{\delta\}^{T}\left[B_{g}\right]^{T}\left[F_{g}^{P}\right]\left[B_{g}\right]\{\delta\} d x+\frac{M_{0}}{2 I_{y}} \int_{L}\{\delta\}^{T}\left[B_{g}\right]^{T}\left[F_{g}^{M}\right]\left[B_{g}\right]\{\delta\} d x \\
=\frac{P_{0}}{2}\{\delta\}^{T}\left[k_{g}^{P}\right]\{\delta\}+\frac{M_{0}}{2}\{\delta\}^{T}\left[k_{g}^{M}\right]\{\delta\}
\end{gathered}
$$

where $\left[k_{g}^{P}\right]=\frac{1}{A} \int_{L}\left[B_{g}\right]^{T}\left[F_{g}^{P}\right]\left[B_{g}\right] d x$ and $\left[k_{g}^{M}\right]=\frac{1}{I_{y}} \int_{L}\left[B_{g}\right]^{T}\left[F_{g}^{M}\right]\left[B_{g}\right] d x$ are the geometric stiffness matrix of the beam element corresponding to axial $\left(P_{0}\right)$ and end moment ( $M_{0}$ ) loads, respectively.

Now the strain energy (Eq. (23)) and the work done by the external forces (Eq. (25)) for all elements are substituted into the potential energy of the structural system (Eq. (4)), followed by minimisation with respect to the nodal displacements of the structure $\{\Delta\}$, to obtain the final governing equation of the thin-walled cross section beam as:

$$
\left([K]-P_{0}\left[K_{g}^{P}\right]-M_{0}^{y}\left[K_{g}^{M}\right]\right)\{\Delta\}=0
$$

where $[K]$ is the stiffness matrix of the structure, and $\left[K_{g}^{P}\right]$ and $\left[K_{g}^{M}\right]$ are the geometric stiffness matrices for the axial $(P)$ and end moment $\left(M_{y}\right)$ load cases, respectively. These are obtained by assembling their corresponding components of the individual elements.

Eq. (26) can be reduced to a simple Eigen-value problem by taking $M_{0}^{y}=0$ or $P_{0}=0$, and this can be solved to obtain the critical value of the axial load $\left(P_{C R}\right)$ or the critical value of the end moment $\left(M_{C R}\right)$ as the Eigen value. For the beams with eccentric loads or end moments, a geometrically nonlinear analysis could be a better option to consider the second order effect. However, the present study adopted a solution technique based on Eigen value problem as employed by other investigators $[13,14]$ in similar situations to keep the formulation linear and avoid complexities associated with nonlinear analysis. For a beam subjected to combined axial force and end moments and displaying interaction between these loads, one of the load 
parameters should be specified (i.e. $M_{0}^{y}=M_{0}<M_{C R}$ or $P_{0}<P_{C R}$ ), whilst and the other parameter will be the unknown Eigen value that will be solved to obtain its critical value (i.e. $P_{c r}^{i}$ or $M_{c r}^{i}$ ). A given thin-walled beam problem can display multiple buckling modes that will provide multiple Eigen values as well as multiple Eigen vectors and mode shapes, which will be extracted from $\{\Delta\}$.

\section{RESULTS AND DISCUSSION}

In this section, numerical examples of thin-walled composite beams having I and box sections are analysed using the developed modelling approach. Initially, the results predicted are compared and benchmarked against analytical and numerical results available in literature to show the performance of the model proposed herein. After this, the results of parametric studies are presented to demonstrate the effect of different parameters on the buckling behaviour of the considered thin-walled cross section beams.

\subsection{Benchmarking against results from literature}

\subsubsection{Buckling of a simply supported doubly symmetric I-section beam subjected to axial compression}

A thin-walled laminated composite beam having a span of $6 \mathrm{~m}$ is studied assuming plane stress conditions $\left(\sigma_{s}=0\right)$ in the plies. A doubly symmetric I beam cross section is chosen with a flange width of $600 \mathrm{~mm}$ and a depth of $600 \mathrm{~mm}$ for its web. All flange and web plates are assumed to be made of 4 plies of $7.5 \mathrm{~mm}$ thickness (so $30 \mathrm{~mm}$ total thickness), and they are assumed to have identical stacking sequence. Five different stacking sequence configurations (Table 1) are considered to investigate the five different cases of the thinwalled I-beam. All plies are assumed to be made of graphite/epoxy with the following properties: $E_{1}=144 \mathrm{GPa}, E_{2}=9.65 \mathrm{GPa}, G_{12}=G_{13}=4.14 \mathrm{GPa}, G_{23}=3.45 \mathrm{GPa}, v_{12}=0.3$. To show the convergence of the proposed model with respect to element size, a specific case having the stacking sequence of $[0 / 90]_{S}$ is considered and the results are presented in Fig. 4.

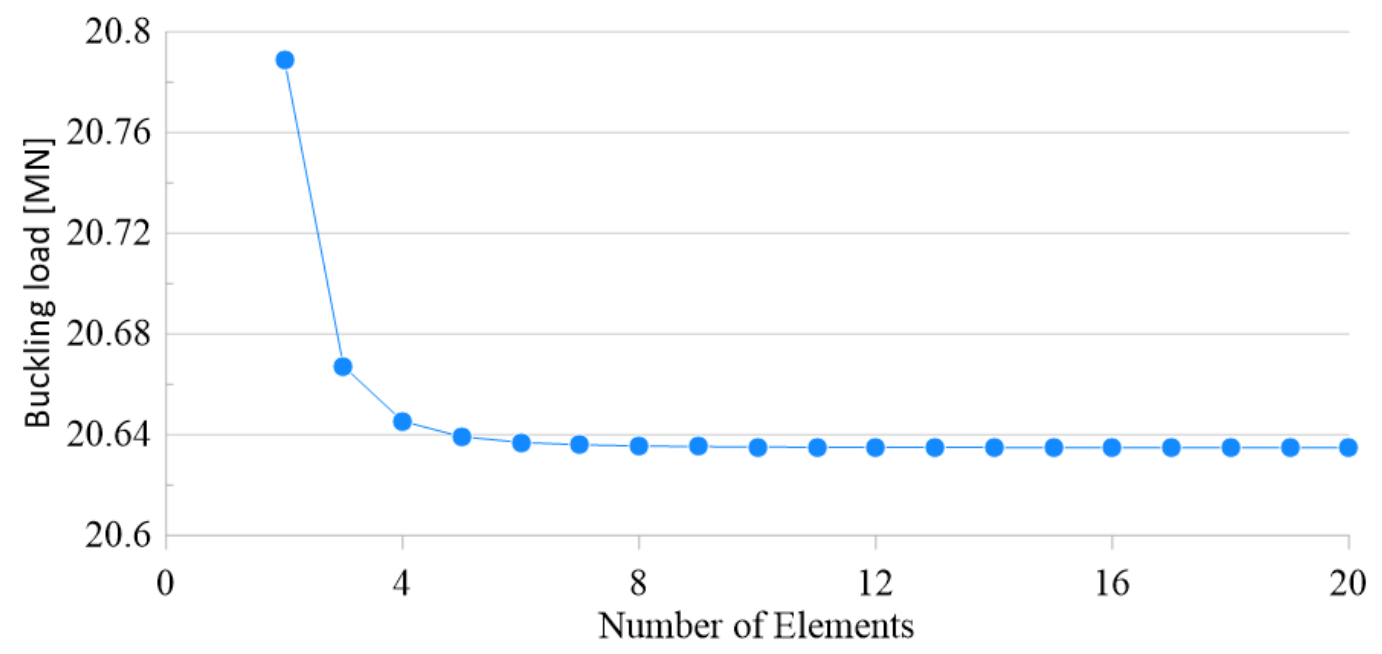

Fig. 4: Predicted buckling load of a simply supported double symmetric composite Isection $\left([0 / 90]_{S}\right)$ beam vs. number of elements 
Fig. 4 shows that the predicted buckling load converges when the number of elements is 8 or more. Based on this observation, all other composite beams studied ahead are analysed with 10 elements unless mentioned otherwise.

The critical buckling loads predicted by the modelling approach developed in this study is shown in Table 1 for all five composite lay-up cases (outer right column). Table 1 also shows the corresponding buckling loads predicted by Vo \& Lee [17], Machado \& Cortinez [24], and Back \& Will [25]. Considering the results predicted by the detailed 3D finite element model (ABAQUS - high computational cost) as reference results in terms of accuracy, the proposed $1 \mathrm{D}$ beam element model (high computational efficiency) performed comparatively better than other modes. Though the model of Vo and Lee [15] performed well, the problem of their formulation for accommodating shear deformation has been explained in Section 1.

Table 1: Critical buckling load (in MN) of a simply supported doubly symmetric composite I-section beam

\begin{tabular}{lllllll}
\hline \multirow{2}{*}{ Lay-ups } & \multicolumn{2}{l}{ Machado \& Cortinez [24] } & \multicolumn{2}{l}{ Back \& Will [25] } & $\begin{array}{l}\text { Vo \& Lee } \\
{[15]}\end{array}$ & $\begin{array}{l}\text { Present } \\
\text { model }\end{array}$ \\
\cline { 2 - 7 } & No shear & Incl. shear & ABAQUS & Incl. shear & With shear & Incl. shear \\
\hline$[0]_{4}$ & 42.11 & 33.18 & 30.78 & 28.85 & 30.38 & 30.93 \\
{$[ \pm 30]_{S}$} & - & - & 13.06 & 13.17 & 13.17 & 13.16 \\
{$[ \pm 45]_{S}$} & 4.45 & 4.44 & 4.41 & 4.41 & 4.41 & 4.41 \\
{$[ \pm 60]_{S}$} & - & - & 2.89 & 2.89 & 2.88 & 2.88 \\
{$[0 / 90]_{S}$} & 22.57 & 19.84 & 20.41 & 20.63 & 20.63 & 20.63 \\
\hline
\end{tabular}

\subsubsection{Buckling of a cantilever mono-symmetric I-section beam subjected to axial compression}

A cantilever mono-symmetric I section beam length of $1.0 \mathrm{~m}$ is investigated for 7 different wall stacking sequences (see Table 2) assuming identical lay-up for all section walls in each case. The web of the beam is assumed to be $50 \mathrm{~mm}$ deep, and the top and bottom flanges are $30 \mathrm{~mm}$ and $50 \mathrm{~mm}$ wide, respectively. The web and flange walls/plates are made of 16 layers/plies each $0.13 \mathrm{~mm}$ thick with a symmetrical $[ \pm \theta]_{4 S}$ lay-up. The material assumed for all the layers is glass/epoxy with the following elastic properties $E_{1}=53.78 \mathrm{GPa}, E_{2}=17.93$ $\mathrm{GPa}, G_{12}=G_{13}=8.96 \mathrm{GPa}, G_{23}=3.45, \mathrm{GPa}, v_{12}=0.25$. The I-section beam has been analysed with the model proposed herein, and the critical buckling loads obtained for the 7 different stacking sequences are presented in Table 2 along with numerical results reported by Kim et al. [16], and Vo and Lee [15]. The comparison of the results demonstrates an excellent match between the predictions obtained using the element proposed here and the results from [15, $16]$.

\subsubsection{Buckling of a simply supported I-section beam under axial load and end moments}

A composite I-section beam having a span of $l=8 \mathrm{~m}$ is analysed adopting a plane stress condition $\left(\sigma_{s}=0\right)$ for the plies. Both flanges are assumed to be $100 \mathrm{~mm}$ wide, and the section is assumed to be $200 \mathrm{~mm}$ deep $(d)$. All section walls are made of 2 plies each $2.5 \mathrm{~mm}$ thick (total thickness: $t=5 \mathrm{~mm}$ ) with unidirectional $[0]_{2}$ lay-up for the top flange and the 
web, while the bottom flange is assumed to have a $[ \pm \theta]$ lay-up. The material used for all the layers is assumed to have the following (normalised) elastic parameters: $E_{1} / E_{2}=25$, $G_{12} / E_{2}=0.6, G_{13}=G_{23}=G_{12}, v_{12}=0.25$. The I-beam is first analysed with the proposed model to obtain the critical buckling load $\left(P_{c r}\right)$ when the end moment is zero. Then, under the action of three different values of the axial force $\left(P_{0}<P_{c r}\right)$, the critical end buckling moments $\left(M_{c r}^{i}\right)$ corresponding to each of the different value of $P_{0}$ interactive scenarios are calculated. Note that $M_{c r}^{i}=M_{c r}$ for the case of no axial preload, i.e. $P_{0}=0$. These results, expressed in nondimensional form $\left(\bar{P}_{c r}=P_{c r} l^{2} /\left(d^{3} t E_{2}\right) ; \bar{M}_{c r}^{i}=M_{c r}^{i} l /\left(d^{3} t E_{2}\right)\right)$, are presented in Table 3 along with results obtained from Vo and Lee [14]. Table 3 shows that the predictions of the modelling approach proposed here show a good correlation with the results of [14]. Further, and further that the effect of shear deformation is observable for the cases of end moment loading (only included in present model).

Table 2: Critical buckling load $(\mathrm{N})$ of a mono-symmetric cantilever composite I-section beam with a symmetrical layup $[ \pm \theta]_{4 S}$

\begin{tabular}{llll}
\hline Lay-ups & Kim et al. [16] & Vo and Lee [15] & Present model \\
\cline { 2 - 4 } & No Shear & Incl. shear & Incl. shear \\
\hline$[0]_{16}$ & 2998.2 & 2993.2 & 2994.5 \\
{$[ \pm 15]_{4 S}$} & 2811.8 & 2803.6 & 2803.3 \\
{$[ \pm 30]_{4 S}$} & 2199.7 & 2184.7 & 2185.1 \\
{$[ \pm 45]_{4 S}$} & 1561.9 & 1546.0 & 1547.2 \\
{$[ \pm 60]_{4 S}$} & 1241.3 & 1227.8 & 1229.0 \\
{$[ \pm 75]_{4 S}$} & 1134.5 & 1126.7 & 1127.9 \\
{$[0 / 90]_{4 S}$} & 2113.9 & 2100.6 & 2101.8 \\
\hline
\end{tabular}

Table 3: Critical buckling load $\bar{P}_{c r}$ and end moment $\bar{M}_{c r}^{i}$ with axial preload of a composite Ibeam (bottom flange: $[ \pm \theta]$, web and top flange: $[0]_{2}$ )

\begin{tabular}{|c|c|c|c|c|c|c|c|c|c|}
\hline \multirow{2}{*}{$\frac{P_{0}}{P_{c r}}$} & \multirow{2}{*}{$\begin{array}{c}\text { Critical } \\
\text { Load }\end{array}$} & \multirow{2}{*}{ Reference } & \multicolumn{7}{|c|}{ Fiber Angle $\theta$ (degree) } \\
\hline & & & 0 & 15 & 30 & 45 & 60 & 75 & 90 \\
\hline & $\bar{P}$ & Vo \& Lee [14] * & 5.153 & 4.565 & 2.771 & 1.631 & 1.259 & 1.140 & 1.112 \\
\hline & $P_{c r}$ & Present + & 5.139 & 4.492 & 2.780 & 1.576 & 1.242 & 1.134 & 1.109 \\
\hline \multirow{2}{*}{-0.5} & \multirow{2}{*}{$\bar{M}_{c r}^{i}$} & Vo \& Lee [14] * & 10.175 & 9.233 & 6.071 & 4.265 & 3.655 & 3.448 & 3.397 \\
\hline & & Present + & 10.183 & 9.405 & 6.160 & 4.427 & 3.650 & 3.469 & 3.374 \\
\hline \multirow{2}{*}{0} & \multirow{2}{*}{$\bar{M}_{c r}^{i}$} & Vo \& Lee [14] * & 7.370 & 6.883 & 4.895 & 3.597 & 3.117 & 2.948 & 2.905 \\
\hline & & Present + & 7.372 & 6.885 & 4.833 & 3.540 & 3.184 & 2.821 & 2.821 \\
\hline \multirow{2}{*}{0.5} & \multirow{2}{*}{$\bar{M}_{c r}^{i}$} & Vo \& Lee [14] * & 4.451 & 4.042 & 2.498 & 1.819 & 1.621 & 1.553 & 1.536 \\
\hline & & Present + & 4.446 & 4.244 & 2.456 & 1.866 & 1.688 & 1.612 & 1.416 \\
\hline
\end{tabular}

\subsubsection{Buckling of a simply supported I-section beam under eccentric axial compression}

The behaviour of a $5 \mathrm{~m}$ long I-section beam subjected to eccentric axial loading as shown in Fig. 5 is investigated. The application of a compression load with a constant known 
eccentricity (e) will induce a proportional end moment $\left(M_{0}=P_{0} e\right)$. This enabled Eq. (26) to be expressed in terms of a single unknown load parameter $\left(P_{0}\right)$, and the solution of this equation provides the critical value of this load $\left(P_{c r}^{i}\right)$ as the eigenvalue. For this sample case, all the section walls (including the web plate) are assumed to be $50 \mathrm{~mm}$ wide and made of 16 layers each $0.13 \mathrm{~mm}$ thick with a symmetrical $[ \pm \theta]_{4 S}$ lay-up. The material for all the layers is glass/epoxy assuming the following elastic properties: $E_{1}=53.78 \mathrm{GPa}, E_{2}=17.93 \mathrm{GPa}, G_{12}=$ $G_{13}=8.96 \mathrm{GPa}, G_{23}=3.45 \mathrm{GPa}, v_{12}=0.25$.

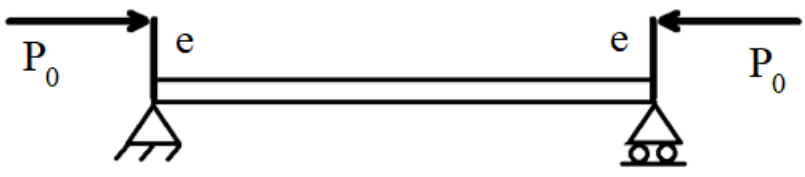

Fig. 5: Simply supported beam under eccentric axial load

The I-section beam has been analysed using the proposed model for three distinct values of the eccentricity; $e=0, \mathrm{~h} / 4$ and $\mathrm{h} / 2$, where $h$ is the depth of the beam. The predicted values of $P_{c r}^{i}$ by the proposed model are presented in Table 4 along with the results of Vo and Lee [14] and Kim et al. [26]. Again, it is found that predictions of the present model are in good agreement with the results obtained from ABAQUS [26] (a detailed 3D shell based finite element model using the commercial software Abaqus) as well as the predictions of [14].

Table 4: Effect of eccentricities on critical buckling loads $(\mathrm{N})$ of a composite I-beam with a symmetrical $[ \pm \theta]_{4 S}$ lay-up for all walls

\begin{tabular}{|c|c|c|c|c|c|c|c|}
\hline \multirow[b]{2}{*}{$\mathrm{e}$} & \multirow{2}{*}{ Reference } & \multicolumn{6}{|c|}{ Layups } \\
\hline & & {$[0]_{16}$} & {$[ \pm 15]_{4 S}$} & {$[ \pm 30]_{4 S}$} & {$[ \pm 45]_{4 S}$} & {$[ \pm 60]_{4 S}$} & {$[ \pm 75]_{4 S}$} \\
\hline \multirow{2}{*}{0} & Vo \& Lee $[14]+$ & 920.80 & 832.00 & 617.80 & 427.60 & 338.40 & 311.70 \\
\hline & Present + & 920.56 & 831.76 & 617.68 & 427.60 & 338.33 & 311.69 \\
\hline \multirow{4}{*}{$\frac{h}{4}$} & Kim et al. ABAQUS & & 809.20 & 608.10 & 423.50 & 335.50 & 308.60 \\
\hline & [26] Analytical * & & 810.70 & 608.70 & 423.70 & 335.60 & 308.60 \\
\hline & Vo \& Lee $[14]+$ & 890.30 & 810.50 & 608.00 & 422.90 & 334.90 & 308.30 \\
\hline & Present + & 890.63 & 810.69 & 608.63 & 423.36 & 334.64 & 308.03 \\
\hline$\underline{h}$ & Vo \& Lee $[14]+$ & 818.60 & 757.50 & 582.20 & 410.00 & 325.30 & 298.80 \\
\hline$\overline{2}$ & Present + & 820.02 & 758.38 & 581.55 & 411.59 & 326.39 & 297.98 \\
\hline
\end{tabular}

\subsubsection{Buckling of a simply supported box-section beam under axial load and end moments}

The effect of different predefined axial loads on the critical end moments causing buckling of an $8 \mathrm{~m}$ long beam having a box section has been investigated as well. The box section is assumed to be of width $b=100 \mathrm{~mm}$ and depth $d=200 \mathrm{~mm}$, and different lay-up sequences are studied. All section walls are assumed to be made of 2 layers, each having a thickness of $2.5 \mathrm{~mm}$ (total thickness: $t=5 \mathrm{~mm}$ ), and with (relative) elastic properties of $E_{1} / E_{2}=25$, $G_{12} / E_{2}=0.6, G_{13}=G_{23}=G_{12}, v_{12}=0.25$. The top and bottom flanges are assumed to have unidirectional $[0]_{2}$ lay-ups, and the webs have $[ \pm \boldsymbol{\theta}]$ lay-ups.

Initially, the box section beam is analysed using the method presented herein to estimate the critical buckling loads $\left(P_{c r}\right)$ with no end moments being applied. Following this, the 
critical end moments $\left(M_{c r}^{i}\right)$ are calculated for three different values of axial preloads; $P_{0}=-0.5 P_{c r}, P_{0}=0$, and $P_{0}=+0.5 P_{c r}$. The results are expressed in non-dimensional form, $\bar{P}_{c r}=P_{c r} l^{2} /\left(d^{3} t E_{2}\right)$ and $\bar{M}_{c r}^{i}=M_{c r}^{i} l /\left(d^{3} t E_{2}\right)$, and presented in Table 5 along with results reported by Vo et al. [13].

Table 5: Critical buckling load $\overline{\mathrm{P}}_{\mathrm{cr}}$ and moment $\bar{M}_{c r}^{i}$ with axial preload of a composite box-beam (flanges: $[0]_{2}$, webs: $[ \pm \theta]$ )

\begin{tabular}{cclccccccc}
\hline \multirow{2}{*}{$P_{0}$} & \multirow{2}{*}{$\begin{array}{c}\text { Critical } \\
P_{c r}\end{array}$} & Load & Reference & \multicolumn{7}{c}{ Fiber Angle $\theta$ (degree) } \\
\cline { 3 - 8 } & & 0 & 15 & 30 & 45 & 60 & 75 & 90 \\
\hline \multirow{2}{*}{$\bar{P}_{c r}$} & Vo et al. [13]* & 36.009 & 29.245 & 13.549 & 7.858 & 6.67 & 6.419 & 6.375 \\
& Present + & 35.510 & 28.917 & 13.479 & 7.834 & 6.653 & 6.403 & 6.359 \\
\hline \multirow{2}{*}{0.5} & \multirow{2}{*}{$\bar{M}_{c r}^{i}$} & Vo et al. [13]* & 3.309 & 4.571 & 3.374 & 2.111 & 1.633 & 1.441 & 1.386 \\
& & Present + & 3.269 & 4.519 & 3.324 & 2.098 & 1.611 & 1.428 & 1.379 \\
\hline \multirow{2}{*}{0} & \multirow{2}{*}{$\bar{M}_{c r}^{i}$} & Vo et al. [13]* & 2.688 & 3.725 & 2.753 & 1.722 & 1.332 & 1.175 & 1.131 \\
& & Present + & 2.660 & 3.681 & 2.711 & 1.712 & 1.315 & 1.165 & 1.125 \\
\hline \multirow{2}{*}{0.5} & \multirow{2}{*}{$\bar{M}_{c r}^{i}$} & Vo et al. [13]* & 1.891 & 2.629 & 1.945 & 1.217 & 0.941 & 0.830 & 0.798 \\
& & Present + & 1.874 & 2.597 & 1.915 & 1.210 & 0.929 & 0.823 & 0.795 \\
\hline
\end{tabular}

* Shear effects not included + $\quad$ Shear effects are included

To study the effects of varying the stacking sequences of the section of the section walls further, the same box section beam is analysed in an exactly the same manner assuming $[\theta]_{2}$ stacking sequence for the top flange and the left web, and $[0]_{2}$ for the right web and the bottom flange. The coupling between the different loads will be more pronounced for the case of unsymmetrical stacking sequence scheme in comparison with the previous case (Table 5). The results predicted by the proposed model are presents in Table 6 along with results presented in. [13]. Table 5 and Table 6 show a good agreement between the results.

Table 6: Critical buckling load $\overline{\mathrm{P}}_{\mathrm{cr}}$ and moment $\bar{M}_{c r}^{i}$ with axial preload of a composite box-beam (top flange and left web: $[\theta]_{2}$, bottom flange and right web: $[0]_{2}$ )

\begin{tabular}{cccccccccc}
\hline \multirow{2}{*}{$P_{0}$} & \multirow{2}{*}{$\begin{array}{c}\text { Critical } \\
P_{c r}\end{array}$} & Load & Reference & \multicolumn{7}{c}{ Fiber Angle $\theta$ (degree) } \\
\cline { 3 - 9 } & & 0 & 15 & 30 & 45 & 60 & 75 & 90 \\
\hline \multirow{2}{*}{$\bar{P}_{c r}$} & Vo \& Lee [13]* & 36.009 & 30.210 & 17.015 & 9.899 & 7.918 & 7.454 & 7.370 \\
& & Present + & 35.510 & 29.964 & 16.820 & 9.808 & 7.870 & 7.415 & 7.304 \\
\hline \multirow{2}{*}{0.5} & \multirow{2}{*}{$\bar{M}_{c r}^{i}$} & Vo \& Lee [13]* & 3.309 & 3.366 & 2.834 & 2.133 & 1.743 & 1.571 & 1.523 \\
& & Present + & 3.283 & 3.346 & 2.842 & 2.133 & 1.742 & 1.570 & 1.519 \\
\hline \multirow{2}{*}{0} & \multirow{2}{*}{$\bar{M}_{c r}^{i}$} & Vo \& Lee [13]* & 2.688 & 2.741 & 2.322 & 1.748 & 1.427 & 1.285 & 1.246 \\
& & Present + & 2.673 & 2.713 & 2.303 & 1.731 & 1.416 & 1.277 & 1.236 \\
\hline \multirow{2}{*}{0.5} & \multirow{2}{*}{$\bar{M}_{c r}^{i}$} & Vo \& Lee [13]* & 1.891 & 1.922 & 1.625 & 1.232 & 1.008 & 0.909 & 0.881 \\
& & Present + & 1.884 & 1.897 & 1.605 & 1.209 & 0.991 & 0.895 & 0.867 \\
\hline
\end{tabular}

* Shear effects not included $\quad+$ Shear effects included 


\subsection{Parametric Study}

\subsubsection{Buckling of a fully clamped I-section beam subjected to axial compression loading}

A clamped I-section beam subjected to axial compression loading is considered. The effect of different fibre orientations $(\theta)$ of the bottom flange $\left([\theta]_{2}\right)$ with unaltered laminate lay-up ( $[0 / 45]$ ) for the top flange and the web on the buckling behaviour is studied for different slenderness ratios $(l / d)$ of the beam ( $l$ is length and $d$ is the depth). The beam section is 300 $\mathrm{mm}$ deep and its flanges are $200 \mathrm{~mm}$ wide. All section walls are assumed to be made of 2 layers having a thickness of $2.5 \mathrm{~mm}$ giving a total wall thickness $(t)$ of $5 \mathrm{~mm}$, and the normalised elastic properties of these layers are specified to: $E_{1} / E_{2}=25, G_{12} / E_{2}=0.6, G_{13}=G_{23}$ $=G_{12}, v_{12}=0.25$. The asymmetry with respect to the top and bottom flange laminations is responsible for producing nonzero off-diagonal terms in the cross-sectional stiffness matrix $\left(F_{13}, F_{16}, F_{24}, F_{35}\right.$, see Appendix B [23]), which in turn introduces coupling of different deformation modes. The variation of the critical axial load, as predicted by the proposed model, for varying values of $\theta$, ranging from 0 to $90^{\circ}$, is presented in Fig. 6 as a nondimensional buckling load parameter $\left(\bar{P}=P_{c r} l^{2} /\left(d^{3} t E_{2}\right)\right)$ taking $l / d=5$ (short beam), 10 and 25 (long beam). It is seen that the critical buckling load decreased monotonically with increasing fibre angle $(\theta)$, where the effect is visibly pronounced when $\theta$ is ranging between $20^{\circ}$ and $50^{\circ}$. It is further observed that the effect of varying the slenderness ratio $(l / d)$ is most prominent when $\theta$ is varied between 0 and $20^{\circ}$, reduces gradually with increasing values of $\theta$ , to become negligible beyond $50^{\circ}$. In order to show the contribution of shear deformation, the present formulation is amended to exclude the shear deformation by dropping the terms $\Psi_{y}$ and $\Psi_{z}$. The amended formulation without shear deformation is used to produce in a similar manner and included in Fig. 6. Though a similar trend of results is obtained by the two formulations, but the contribution of shear deformation is found to be significant for $1 / \mathrm{d}=$ 5 (short beam) specifically for lower range of $\theta$ and it is reduced with the increase of $1 / \mathrm{d}$ ratio. It is also clear from the figure that the non-dimensional buckling load for all $1 / \mathrm{d}$ ratios without shear deformation are identical and very close to shear deformable results for a long beam $(1 / d=25)$.

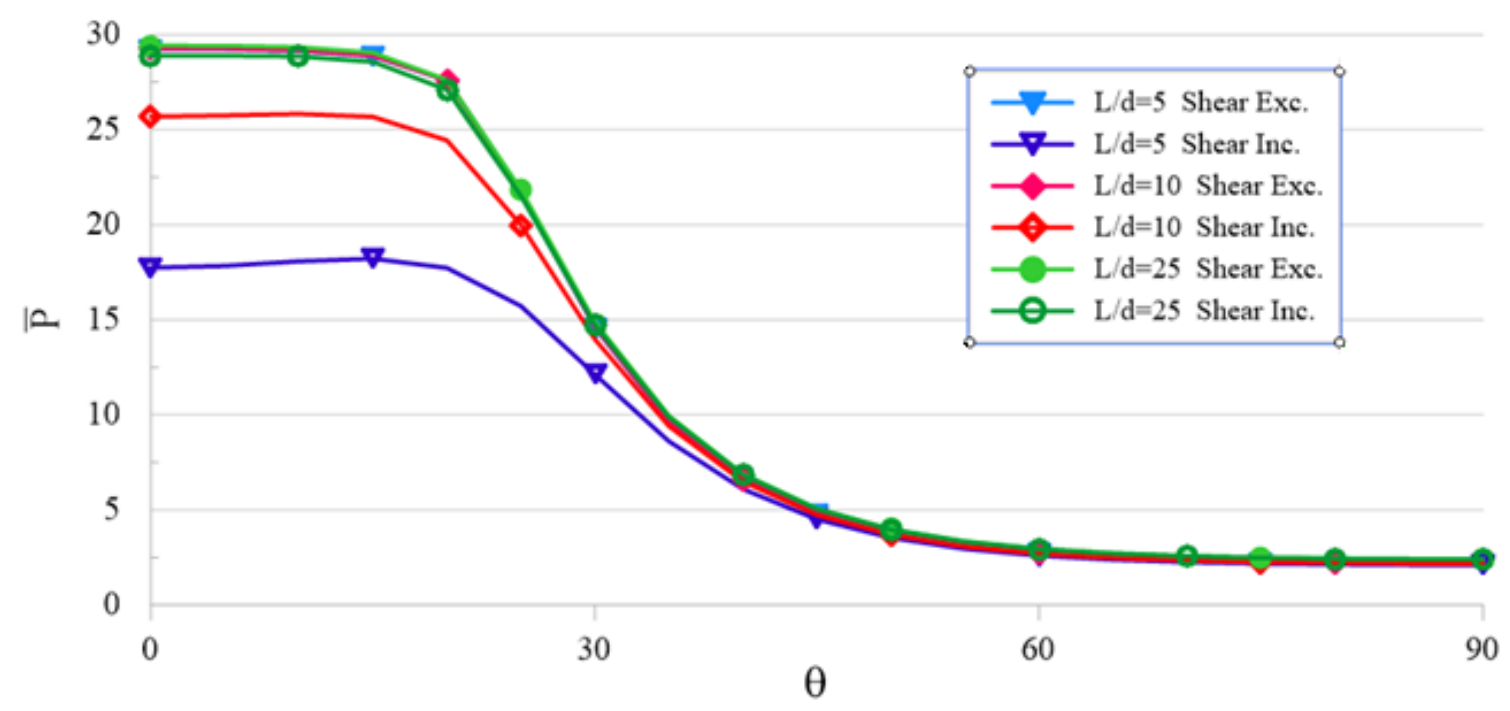

Fig. 6: Variation of buckling load parameter $(\bar{P})$ of a clamped I-section composite beam with respect to fibre angle $(\theta)$ of its bottom flange 
The mode shapes the lateral displacements $v$ and the torsional rotation $\theta_{x}$ (beam twist) corresponding to the specific parametric case of the beam; $\theta=75^{\circ}, l / d=25, \bar{P}_{1}=2.48$, are plotted in Fig. 7, which shows a very pronounced coupled buckling response displaying combined bending and twist.

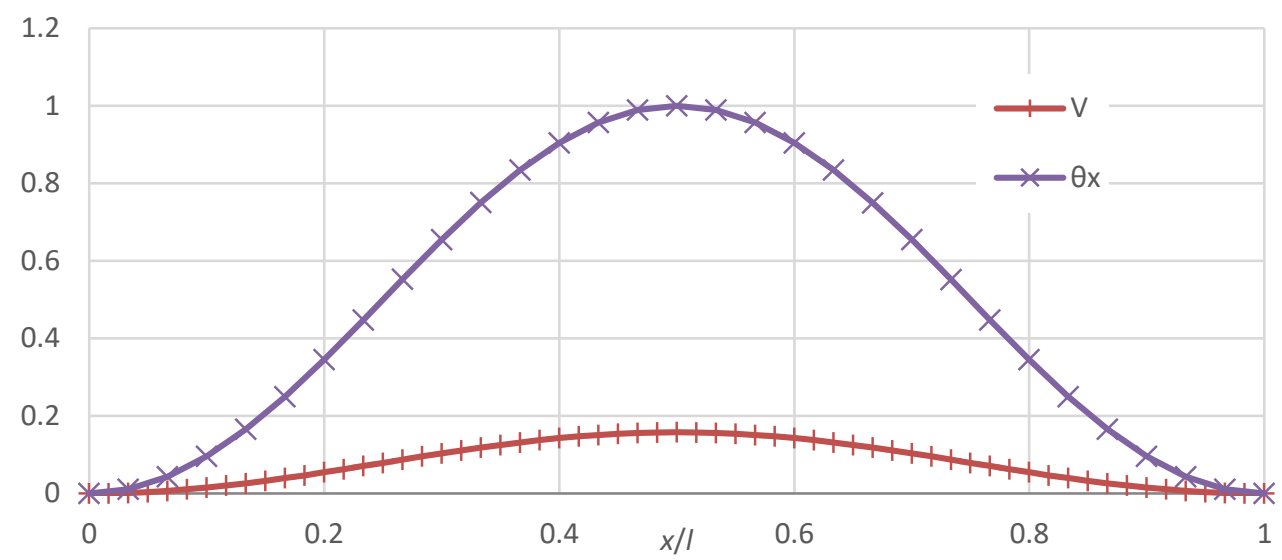

Fig. 7: Typical buckling mode shapes of a clamped I-section composite beam

\subsubsection{Buckling of a simply supported I-section composite beam subjected to eccentric axial compression and end moment preloading}

The case of a simply supported I-section composite beam subjected to combined eccentric axial compression and end moment loading is considered, see Fig. 8. It is assumed that the beam has the same material properties and geometry as discussed in section 3.1.4.

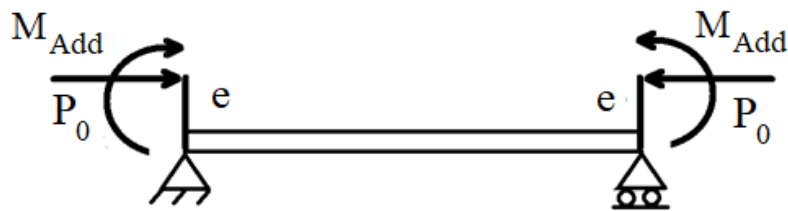

Fig. 8: Simply supported beam subjected to eccentric axial compression and end moment loading

In addition to the eccentric axial compression load $P_{0}$, additional end moments $M_{\text {Add }}$ are applied as a preload, which are combined with the bending moments induced by the eccentric axial load as explained in section 3.1.4. Initially, the value of the axial load $P_{0}$ is taken as zero and the critical value of the end moment, $M_{\text {Add }}=M_{c r}$, is then calculated. Following this, different values of the end moment, $M_{A d d}<M_{c r}$, are applied as preloading, and the critical value of the eccentric axial load $P_{c r}^{i}$ is calculated. Utilising these results, the interaction curves for the eccentric axial force, $P_{0}=P_{c r}^{i}$, and the preloading end moment, $M_{\text {Add }}=M_{c r}^{i}$, which produce buckling of the I-section beam, is plotted in Fig. 9 for three different eccentricities, $e=0, h / 2$ and $h$, and three different fibre angles, $\theta=0,30^{\circ}$ and $60^{\circ}$, for all section walls having $[ \pm \theta]_{4 s}$ lay-up. 


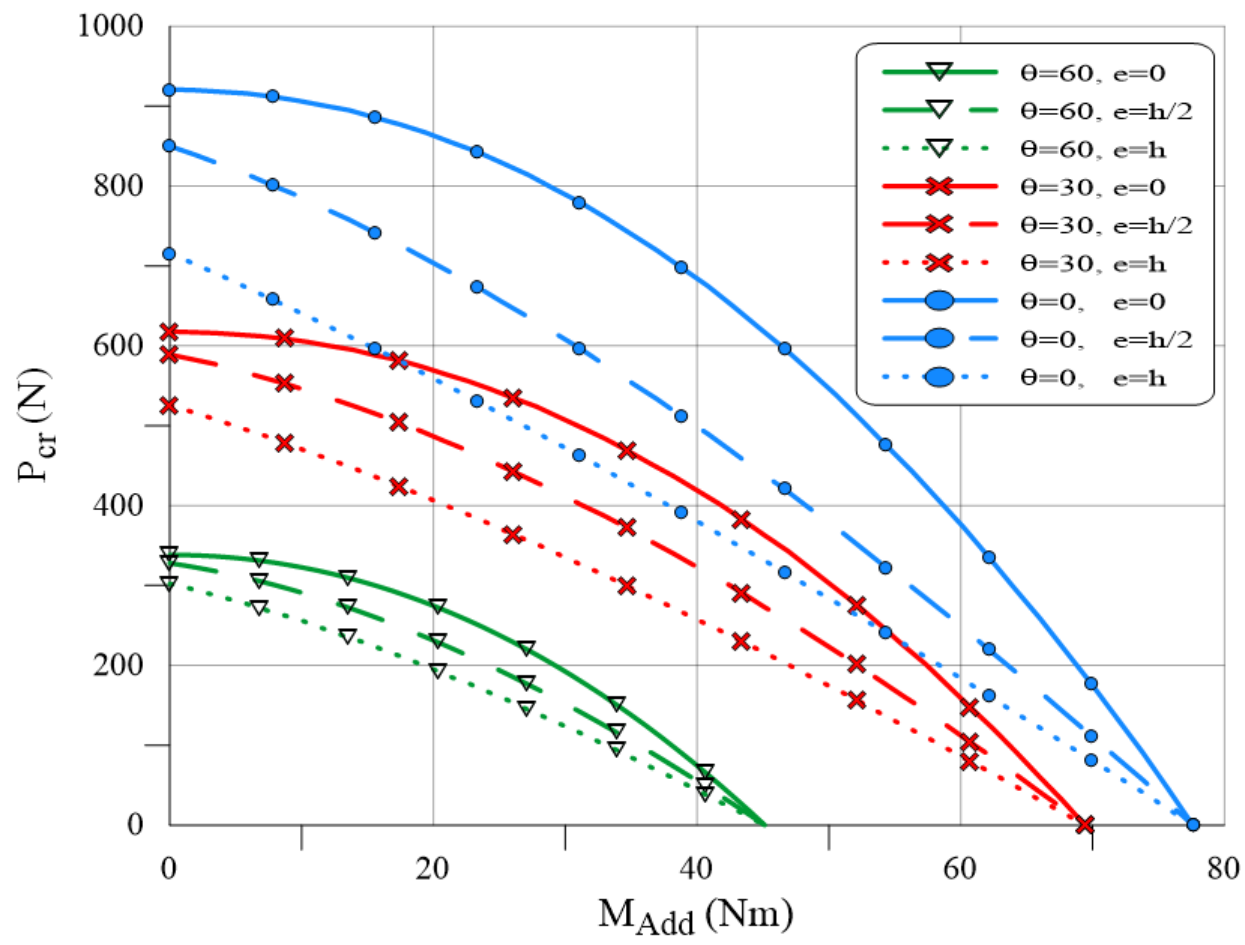

Fig. 9: Interaction between the eccentric axial loads and preloaded end moments for the buckling of a composite I-section beam

Fig. 9 shows that both the critical values of the axial force $P_{c r}^{i}$ and the end moment $M_{\text {Add }}^{i}$ decrease with increasing fibre angle $\theta$. The reason for this is that the cross section stiffness reduces when the fibre angle $\theta$ is increased. Further, it is observed that the critical values of the axial loads and end moments are reduced when the loading eccentricity $\boldsymbol{e}$ is increased as expected.

\subsubsection{Buckling of a cantilever I-section composite beam subjected to axial and end moment loadings}

A cantilever I-section beam subjected to axial and end moment loading is considered, with a focus of investigating a wide range of interactions between the axial compression and the end moment loads. The following beam dimensions are assumed; span $l=8 \mathrm{~m}$, flange width $b=100 \mathrm{~mm}$, web depth $d=200 \mathrm{~mm}$. It is further assumed that all laminated section walls are of $[ \pm \theta]_{3}$ lay-up, and that each ply is $1.25 \mathrm{~mm}$ thick (total thickness $t=7.5 \mathrm{~mm}$ ). The following normalised material properties are assumed: $E_{1} / E_{2}=25, G_{12} / E_{2}=0.6, G_{13}=G_{23}=G_{12}$, $v_{12}=0.25$. Initially the I-section beam is first analysed assuming only axial loading (i.e. no end moment) to determine the critical value, $P_{c r}$, and following that the case of pure end moment loading (i.e. no axial compression load) is analysed to evaluate $M_{c r}$. In the next stage, a parametric study is conducted in which the axial force $P_{0}$ is applied as a preload and varied over a wide range from $P_{0} / P_{c r}=0.8$ to $P_{0} / P_{c r}=-0.8$ (axial tension) in increments of 0.2 , followed by calculation of the critical end moment $M_{c r}^{i}$ for each value of the axial preload. The results are expressed in non-dimensional form $\bar{M}_{c r}^{i}=M_{c r}^{i} l /\left(d^{3} t E_{2}\right)$ and presented in Table 7 for different values of $\boldsymbol{\theta}$ ranging from 0 to $90^{0}$ with increments of $15^{\circ}$. The results show that there is a stabilizing effects of axial tension on the buckling of the member for all 
values of $\boldsymbol{\theta}$. Also, for all preload values, it is observed that $\bar{M}_{c r}^{i}$ increases while $\boldsymbol{\theta}$ increases from 0 to $15^{0}$ whereas $\bar{M}_{c r}^{i}$ decreases monotonically as $\theta$ increases beyond $15^{0}$.

Table 7: Critical end moment $\bar{M}_{c r}^{i}$ for buckling of axially preloaded cantilever composite I-section beam with $[ \pm \theta]_{3}$ lay-up in all section walls

\begin{tabular}{cccccccc}
\hline$P_{0}$ & \multicolumn{7}{c}{ Fiber Angle $\boldsymbol{\theta}$ (degree) } \\
\cline { 2 - 8 }$P_{c r}$ & 0 & 15 & 30 & 45 & 60 & 75 & 90 \\
\hline-0.8 & 12.8825 & 13.5666 & 7.5088 & 3.2986 & 1.9903 & 1.5811 & 1.4801 \\
\hline-0.6 & 11.7575 & 12.5667 & 7.0303 & 3.0983 & 1.8704 & 1.4853 & 1.3901 \\
\hline-0.4 & 10.6225 & 11.5416 & 6.5300 & 2.8873 & 1.7439 & 1.3843 & 1.2953 \\
\hline-0.2 & 9.4740 & 10.4841 & 6.0025 & 2.6629 & 1.6092 & 1.2769 & 1.1945 \\
\hline 0.0 & 8.3064 & 9.3833 & 5.4398 & 2.4216 & 1.4641 & 1.1614 & 1.0862 \\
\hline 0.2 & 7.1103 & 8.2217 & 4.8298 & 2.1576 & 1.3051 & 1.0349 & 0.9677 \\
\hline 0.4 & 5.8683 & 6.9689 & 4.1516 & 1.8612 & 1.1265 & 0.8929 & 0.8347 \\
\hline 0.6 & 4.5429 & 5.5639 & 3.3641 & 1.5137 & 0.9166 & 0.7263 & 0.6788 \\
\hline 0.8 & 3.0263 & 3.8429 & 2.3605 & 1.0661 & 0.6459 & 0.5116 & 0.4780 \\
\hline
\end{tabular}

Similarly, a parametric study is conducted in which the end moment $M_{0}$ is applied as a preload and varied over the range from $M_{0} / M_{c r}=0$ to 0.9 in increments of 0.1 , followed by calculation of the critical axial load $P_{c r}^{i}$ for each value of the end moment preload. The results are presented in Table 8 expressed in non-dimensional form $\bar{P}_{c r}^{i}=P_{c r}^{i} l /\left(d^{3} t E_{2}\right)$ for the same range of fibre orientations $\theta$. Results shows that the value of $\bar{P}_{c r}^{i}$ decreases monotonically with the increase of $\boldsymbol{\theta}$ for all preload values.

\subsubsection{Buckling of a simply supported I-section composite beam subjected to axial and end}

\section{moment loadings}

In this section the behaviour of a $10 \mathrm{~m}$ long I-section beam is studied in a similar manner as in the previous example analysing four different values of the flange width $(b)$ and web height $(d)$, while maintaining same cross-sectional area and wall thickness for all four cases. Fixed ply orientation $\left(\left[0 / 30^{\circ} /-30^{\circ} / 90^{\circ}\right]_{S}\right)$ is assumed for the web and flange plates, where each ply is assumed to $1.25 \mathrm{~mm}$ with the following normalised elastic properties: $E_{1} / E_{2}=25, G_{12} / E_{2}=0.6, G_{13}=G_{23}=G_{12}, v_{12}=0.25$. The variation of critical axial load for the buckling of the four I-section beam cases subjected to preloading end moments are plotted in Fig. 10. Similarly, Fig. 11 presents the variation of the critical end moments causing buckling of I section beams when subjected to axial preloads. Both these figures (Figs. 10 and 11) show that the buckling resistance of these beams having same mass enhances with the increase of $b / d$ ratio of the beam section i.e., a wide flanged beam performs better. In this case, the beam section with highest $\mathrm{b} / \mathrm{d}$ ratio $(b=0.175, d=0.150)$ outperformed the other sections in terms of axial load and end moment buckling capacity. 
Table 8: Critical axial force $\bar{P}_{c r}^{i}$ for buckling of end moment preloaded cantilever composite I-section beam with $[ \pm \theta]_{3}$ lay-up for all walls under preloaded end moments

\begin{tabular}{cccccccc}
\hline$M_{0}$ & \multicolumn{7}{c}{ Fiber Angle $\boldsymbol{\theta}$ (degree) } \\
\cline { 2 - 8 }$M_{\text {cr }}$ & 0 & 15 & 30 & 45 & 60 & 75 & 90 \\
\hline 0.0 & 5.1552 & 4.0337 & 1.4082 & 0.4551 & 0.2562 & 0.2141 & 0.2068 \\
\hline 0.1 & 5.0673 & 3.9833 & 1.3930 & 0.4504 & 0.2536 & 0.2119 & 0.2046 \\
\hline 0.2 & 4.8156 & 3.8341 & 1.3476 & 0.4362 & 0.2456 & 0.2052 & 0.1982 \\
\hline 0.3 & 4.4289 & 3.5912 & 1.2725 & 0.4126 & 0.2324 & 0.1942 & 0.1875 \\
\hline 0.4 & 3.9399 & 3.2625 & 1.1683 & 0.3799 & 0.2140 & 0.1787 & 0.1726 \\
\hline 0.5 & 3.3767 & 2.8572 & 1.0361 & 0.3380 & 0.1905 & 0.1591 & 0.1535 \\
\hline 0.6 & 2.7603 & 2.3849 & 0.8771 & 0.2872 & 0.1620 & 0.1352 & 0.1304 \\
\hline 0.7 & 2.1055 & 1.8551 & 0.6924 & 0.2277 & 0.1285 & 0.1072 & 0.1034 \\
\hline 0.8 & 1.4228 & 1.2762 & 0.4837 & 0.1598 & 0.0903 & 0.0753 & 0.0726 \\
\hline 0.9 & 0.7193 & 0.6557 & 0.2524 & 0.0838 & 0.0474 & 0.0395 & 0.0381 \\
\hline
\end{tabular}

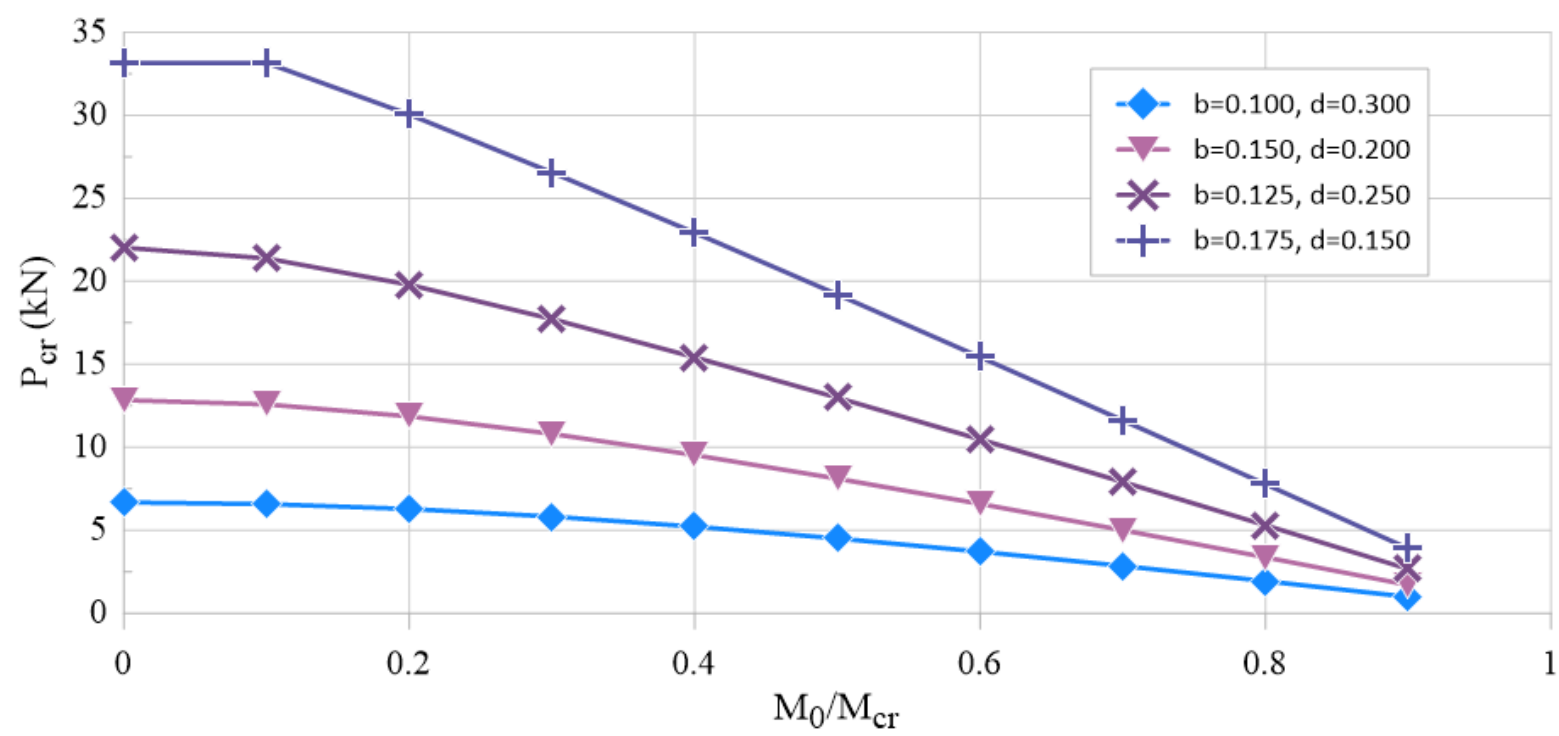

Fig. 10: Variation of buckling loads of composite I-section beams having the same cross section with different sectional parameters subjected to different end moment preloading 


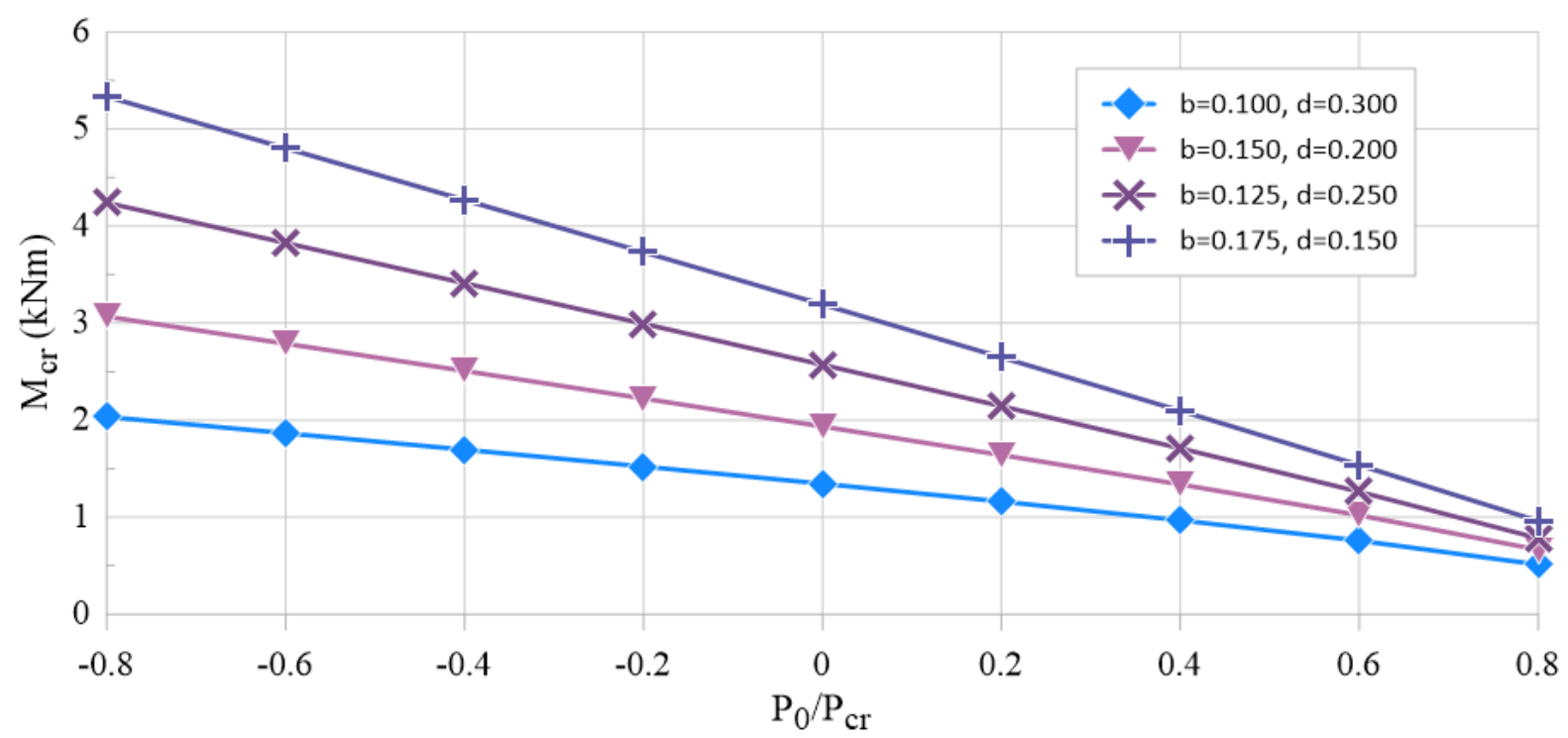

Fig. 11: Variation of end critical moment loading causing buckling of composite I-section beams having the same cross section with different sectional parameters subjected to different axial preloads

\subsubsection{Buckling of a simply supported box-section composite beam subjected to axial and end moment loadings}

In this section a simply supported composite box section beam subjected axial and end moment loading is considered. The beam is assumed to be of span $l=8 \mathrm{~m}$ with flanges of width of $b=100 \mathrm{~mm}$, and depth of the webs $d=200 \mathrm{~mm}$. The analyses conducted focus on the interactions between the axial and end moment loadings in a similar manner as shown in the previous sections. It is assumed that laminated sections are of $[ \pm \theta]_{2}$ lay-up, with each ply assumed to be $1.25 \mathrm{~mm}$ thick, and assuming the following normalised elastic material properties: $E_{1} / E_{2}=25, G_{12} / E_{2}=0.6, G_{13}=G_{23}=G_{12}, v_{12}=0.25$. Table 9 presents the variation of the non-dimensional critical end moments causing buckling of the box section beams subjected to axial preloads. Similarly, it is observed for all axial preloading values that $\bar{M}_{c r}^{i}$ increases with the increase of $\boldsymbol{\theta}$ from 0 to $15^{0}$ while $\bar{M}_{c r}^{i}$ decreases monotonically as $\boldsymbol{\theta}$ increases from $15^{0}$ to $90^{\circ}$. Also, Table 10 presents the variation of the non-dimensional critical axial load for the buckling of the box section beams when subjected to preloaded end moments. The table shows that the value of $\bar{P}_{c r}^{i}$ decreases monotonically with the increase of $\boldsymbol{\theta}$ for all moment preloading values.

\subsubsection{Buckling of a simply supported optimized box-section beam subjected to axial and end moment loading}

Similar to the previous example, the behaviour of a $8 \mathrm{~m}$ long composite box-section beam is investigated considering four different values of flange width $(b)$ and web height $(d)$, while maintaining the same cross-sectional area and section wall thickness for all four cases. In this case, a fixed ply orientation $\left([ \pm 60]_{2}\right)$ is used for the all the laminated section walls where each ply is $1.25 \mathrm{~mm}$ thick and assuming the following normalised elastic properties: $E_{1} / E_{2}=25, G_{12} / E_{2}=0.6, G_{13}=G_{23}=G_{12}, v_{12}=0.25$. 
The variation of critical axial load for the buckling of the four different box-beam cases when subjected to varying preload end moments is shown in Fig. 12. In the same way, Fig. 13 presents the variation of critical end moments causing buckling of the four different boxbeam cases when subjected to varying levels of axial preloading. Fig. 12 shows that the resistance in terms of axial buckling load capacity of the beam with square section ( $b=0.200, d=0.200)$ is superior over rectangular beams sections having same cross-sectional area. The buckling load capacity is found to deteriorate with the increase of aspect ratio of the cross-section. This is due to the buckling characteristic of box-section beams which undergo lateral buckling in the weakest direction. It is found to be different for I-section beams (Figs. 10 and 11) as they undergo lateral-torsion buckling where a wide flange beam (lower $\mathrm{d} / \mathrm{b}$ ratio) is beneficial. On the other hand, Fig. 13 shows that the rectangular beam section having the highest aspect ratio $(\mathrm{d} / \mathrm{b})(b=0.125, d=0.275)$ provides the highest resistance for end buckling moment and this behaviour is just opposite to that of I-section beam (Fig. 11).

Table 9: Critical buckling moment $\bar{M}_{c r}^{i}$ of a simply supported composite box-section beam with $[ \pm \theta]_{2}$ lay-up in all section walls and subjected to different axial preloads $P_{0} / P_{c r}$

\begin{tabular}{cccccccc}
\hline$P_{0}$ & \multicolumn{7}{c}{ Fiber Angle $\boldsymbol{\theta}$ (degrees) } \\
\cline { 2 - 8 }$P_{c r}$ & 0 & 15 & 30 & 45 & 60 & 75 & 90 \\
\hline-0.8 & 226.70 & 348.48 & 226.18 & 102.07 & 61.31 & 48.37 & 45.14 \\
\hline-0.6 & 213.47 & 328.47 & 213.24 & 96.23 & 57.81 & 45.60 & 42.56 \\
\hline-0.4 & 199.44 & 307.17 & 199.46 & 90.02 & 54.07 & 42.66 & 39.81 \\
\hline-0.2 & 184.41 & 284.30 & 184.65 & 83.34 & 50.06 & 39.49 & 36.86 \\
\hline 0.0 & 168.14 & 259.46 & 168.56 & 76.08 & 45.70 & 36.05 & 33.65 \\
\hline 0.2 & 150.20 & 232.01 & 150.76 & 68.05 & 40.88 & 32.25 & 30.09 \\
\hline 0.4 & 129.92 & 200.87 & 130.56 & 58.93 & 35.40 & 27.93 & 26.06 \\
\hline 0.6 & 105.94 & 163.96 & 106.59 & 48.12 & 28.91 & 22.80 & 21.28 \\
\hline 0.8 & 74.82 & 115.91 & 75.37 & 34.03 & 20.44 & 16.12 & 15.05 \\
\hline
\end{tabular}

Table 10: Critical axial buckling load $\bar{P}_{c r}^{i}$ of a simply supported composite Box-section beam having $[ \pm \boldsymbol{\theta}]_{2}$ lamination for all walls and subjected to different end moment preloads

$$
M_{0} / M_{C R}
$$

\begin{tabular}{cccccccc}
\hline$M_{0}$ & \multicolumn{7}{c}{ Fiber Angle $\boldsymbol{\theta}$ (degree) } \\
\cline { 2 - 8 }$M_{c r}$ & 0 & 15 & 30 & 45 & 60 & 75 & 90 \\
\hline 0.0 & 44.4808 & 35.0107 & 12.2659 & 3.9677 & 2.2344 & 1.8671 & 1.8033 \\
\hline 0.1 & 44.0305 & 34.6596 & 12.1432 & 3.9280 & 2.2120 & 1.8485 & 1.7853 \\
\hline 0.2 & 42.6802 & 33.6066 & 11.7751 & 3.8090 & 2.1450 & 1.7924 & 1.7312 \\
\hline 0.3 & 40.4320 & 31.8519 & 11.1616 & 3.6106 & 2.0333 & 1.6991 & 1.6410 \\
\hline 0.4 & 37.2893 & 29.3962 & 10.3028 & 3.3329 & 1.8769 & 1.5684 & 1.5148 \\
\hline 0.5 & 33.2567 & 26.2402 & 9.1986 & 2.9758 & 1.6758 & 1.4004 & 1.3525 \\
\hline 0.6 & 28.3404 & 22.3849 & 7.8492 & 2.5394 & 1.4301 & 1.1950 & 1.1541 \\
\hline 0.7 & 22.5476 & 17.8317 & 6.2545 & 2.0236 & 1.1396 & 0.9523 & 0.9197 \\
\hline 0.8 & 15.8866 & 12.5820 & 4.4147 & 1.4285 & 0.8045 & 0.6722 & 0.6492 \\
\hline 0.9 & 8.3672 & 6.6374 & 2.3298 & 0.7539 & 0.4246 & 0.3548 & 0.3426 \\
\hline
\end{tabular}




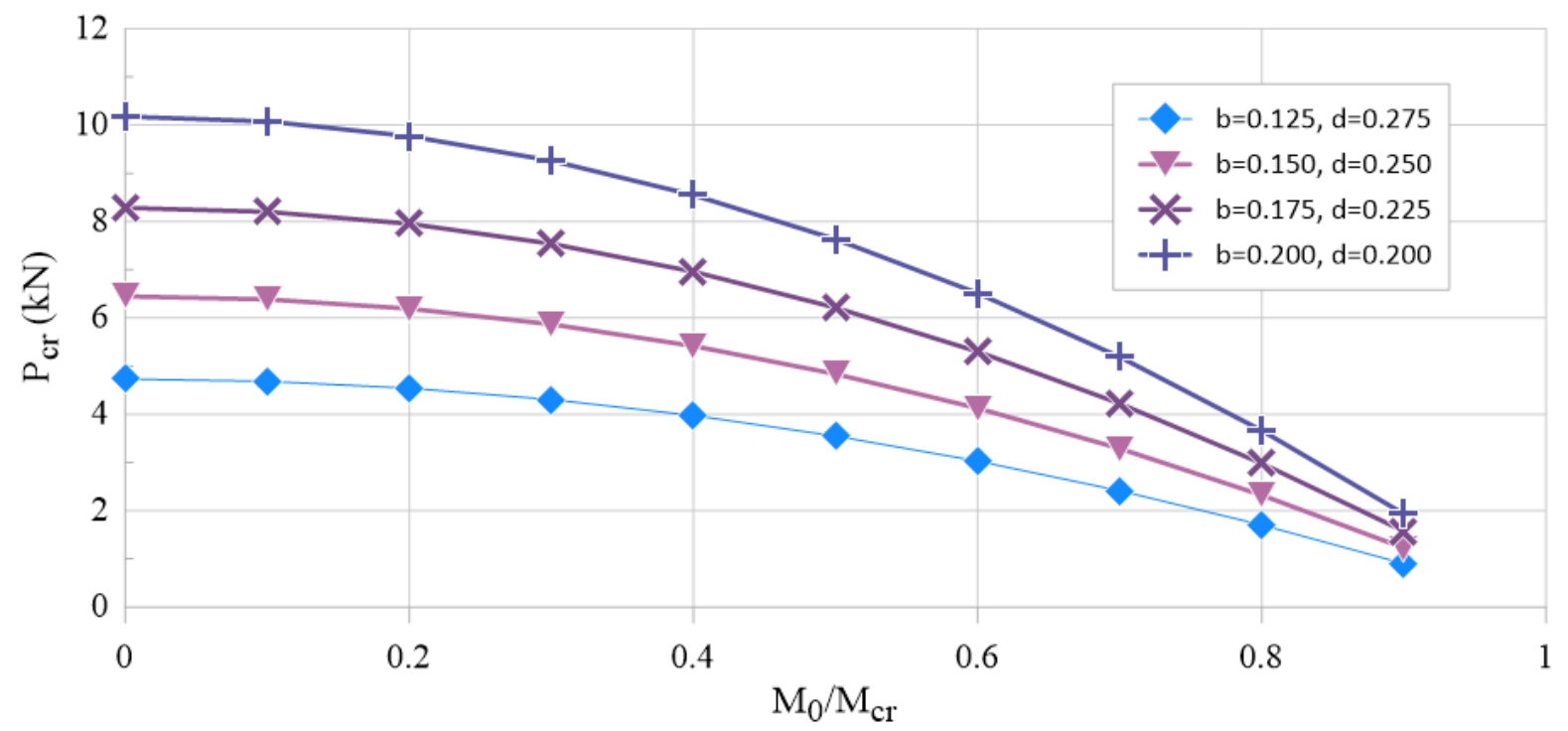

Fig. 12: Variation of buckling loads of composite box-section beams having the same cross section with different flange widths (b) and web heights (d) and subjected to different levels of preload end moments

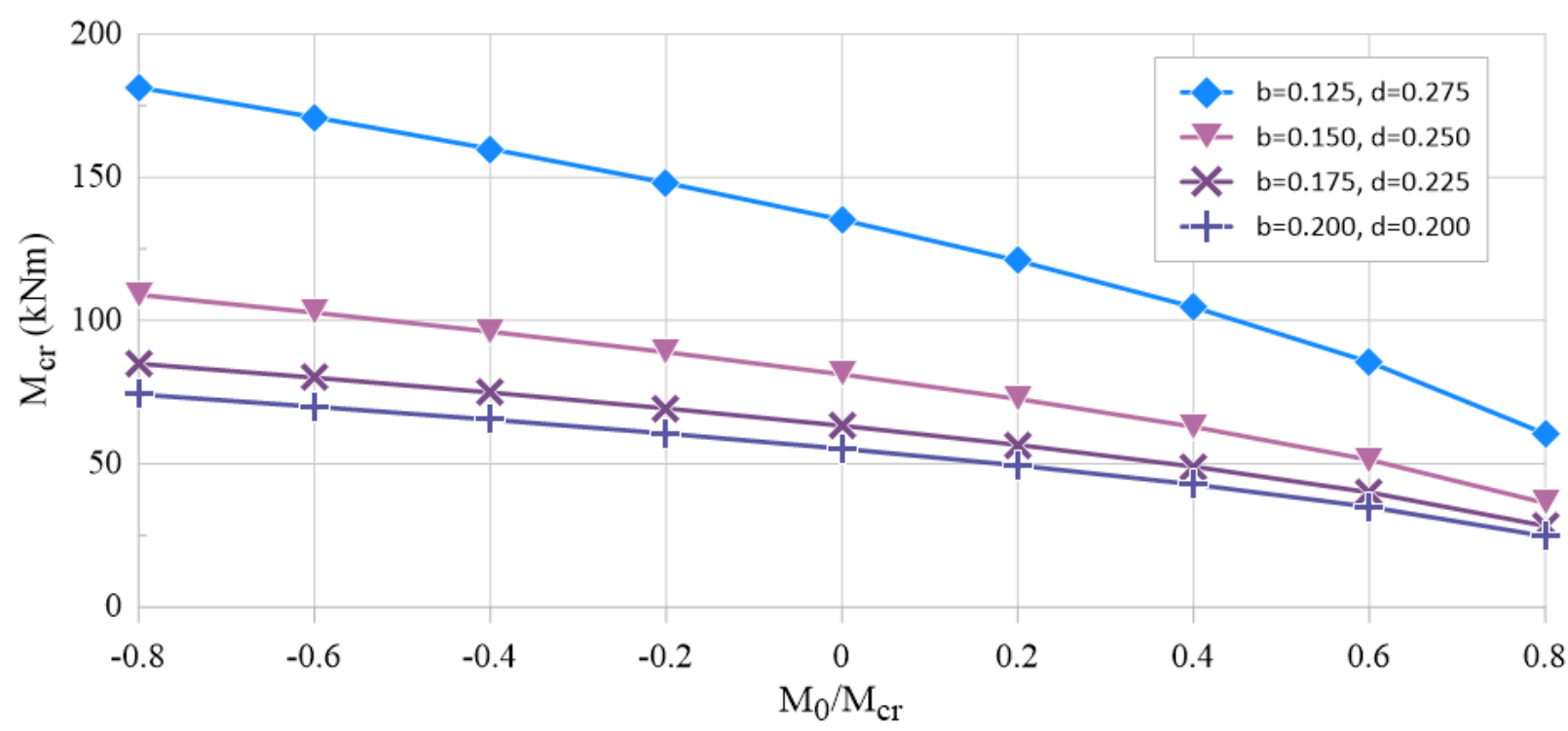

Fig. 13: Variation of critical end moment causing buckling of composite box-section beams having the same cross section with different flange widths (b) and web heights (d) and subjected to different levels of axial preloading

\section{CONCLUSIONS}

A new technique for the buckling analysis of thin-walled composite beams subjected to axial forces and end moment loading has been presented. The new technique is based on onedimensional beam element formulation that helped to improve the computation efficiency significantly in contrast with a typical full-blown three-dimensional finite element model using solid or shell elements. The proposed model is valid for thin-walled open and closed section beams, and is especially well-suited for the analysis of the load response and buckling behaviour of composite beams displaying complex mode interactions. The formulation is general, includes axial deformation, torsion, bi-axial bending and transverse shear deformation as well as out of plane cross-sectional warping. The cross-sectional matrices of 
the beams are derived analytically and includes all the possible couplings between the abovementioned modes of deformation. The effect of shear deformation of the beam section walls is included in the formulation, which typically demands a $\mathrm{C}^{0}$ continuous finite element formulation for the bending deformations of the beam element coupled with transverse shear deformations. Previous attempts [16-18] to include cross-sectional warping effects within the framework of $\mathrm{C}^{0}$ continuity have displayed susceptibility to shear locking problems, which have typically been circumvented by using the reduced integration technique which supresses the problematic terms related to shear energy. However, this affects the solution accuracy, including stress oscillations and other related issues due to inadequate integration of other terms of the strain energy of the structural system. Moreover, a consistent implementation of cross-sectional warping demands a $\mathrm{C}^{1}$ continuous formulation for the torsional deformation due to the appearance of second order derivatives of the torsional rotation (twist) in the strain vector. To overcome this in a $\mathrm{C}^{0}$ continuous formulation requires inclusion of fictitious nodal parameters that cannot be attributed any physical meaning [15]. To overcome these difficulties a $\mathrm{C}^{1}$ continuous formulation is adopted in this research, which includes full integration to achieve correct evaluation of the strain energy. The model proposed overcomes the crucial obstacles by adopting a different formulation for the coupled bending and shear deformations of the beam element which permits the use of full integration. The new modelling technique is used to solve numerical examples of thin-walled laminated composite beams having open (I) and closed (box) sections assuming different boundary conditions, laminated section wall stacking sequences, and different loading conditions. The results produced are thoroughly benchmarked and validated against analytical and numerical results available in literature, and it is shown that the proposed model performs very well in terms of both accuracy and computational efficiency. Finally, the new finite element is used to conduct extensive parametric studies to demonstrate the effect of varying different parameters on the buckling characteristics of composite thin-walled beams subjected to different loading scenarios involving the interactions between axial and end moment loads. It is anticipated that these new results can prove to be useful as benchmarks for future research in this area.

\section{REFERENCES}

[1] N.R. Bauld, L.S. Tzeng, A Vlasov theory for fibre-reinforced beams with thin-walled open cross section, Int. J. of Solid and Struc. 20(3) (1984) 277-97.

[2] R. Chandra, A.D. Stemple, I. Chopra, Thin-walled composite beams under bending, torsion, and extensional load, AIAA Journal 27(7) (1990) 619-626.

[3] C.E.S Cesnik, D.H. Hodges, VABS: A new concept for composite rotor blade cross section modelling, J. of the American Helicopter Society 42(1) (1997) 27-38.

[4] L.P. Kollar, Springer GS. Mechanics of Composite Structures, Cambridge University Press, 2003.

[5] H.A. Salim, J.F. Devalos, Torsion of open and closed thin-walled laminated composite sections, J. of compos. Mat. 39(6) (2005) 497-524.

[6] J. Lee, Flexural analysis of thin-walled composite beams using shear-deformable beam theory, Compos. Struc. 70(2) (2005) 212-222.

[7] L. Librescu, O. Song, Thin-walled Composite Beams, Springer, 2006.

[8] H.X. Nguyen, J. Lee, T.P. Vo, D. Lanc, Vibration and lateral buckling optimisation of thinwalled laminated composite channel-section beams, Compos. Struc. 143(2016) 84-92.

[9] L. Shang, P. Xia, D.H. Hodges, Geometrically exact nonlinear analysis of pre-twisted composite rotor blades, Chinese J. of Aeronautics 31(2) (2018) 300-309. 
[10] M. Gupta, D.H. Hodges, Modelling Thin-Walled Beams using VAM, Structural Dynamics, and Materials Conference, AIAA SciTech Forum, (AIAA 2017-1832), 2017. https://doi.org/10.2514/6.2017-1832.

[11] D. Harursampath, A.B. Harish, D. H. Hodges, Model reduction in thin-walled open-section composite beams using variational asymptotic method. Part I: Theory, Thin-Walled Struc. 117 (2017) 356-366.

[12] K. Kashefi, A.H. Sheikh, MS.M. Ali, MC. Griffith, An efficient modelling approach based on a rigorous cross-sectional analysis for analysing box girder bridge superstructures, Adv. in Struc. Eng. 19(3) (2016) 513-528.

[13] T.P. Vo, J. Lee, Interaction curves for vibration and buckling of thin-walled composite box beams under axial loads and end moments, App. Math. Modelling 34(2010) 3412-3157.

[14] T.P. Vo, J. Lee, Vibration and Buckling of thin-walled composite I-Beams with Arbitrary Layups under axial Loads and End Moments, Mech. of Adv. Mat. and Struc. 20(8) (2013) 652-665.

[15] T.P. Vo, J. Lee, On Sixfold coupled buckling of thin-walled composite beams, Compos. Struc. 90 (2009) 295-303.

[16] N.-I. Kim, D. K. Shin, and M.-Y. Kim, Flexural-Torsional buckling loads for spatially coupled stability analysis of thin-walled composite columns, Adv. in Eng. Softw. 39 (2008) 949-961.

[17] N.-I. Kim, D. K. Shin, and Y.-S. Park, Coupled stability analysis of thin-walled composite beams with closed cross section, Thin-walled Struc. 48 (2010) 581-596.

[18] N.-I. Kim, C.K. Jeon, Coupled Static and Dynamic Analyses of Shear Deformable Composite Beams with Channel-Sections, Mech. Based Design of Struc. and Mach., 2013, https://doi.org/10.1080/15397734.2013.797332.

[19] M.T. Piovan, V.H. Cortinez, Mechanics of shear deformable thin-walled beams made of composite materials, Thin-Walled structures, 45 (2007) 37-62.

[20] F. Ascione, M.Lamberti, G.Razaqpur, Modifications of standard GFRP sections shape and proportions for improved stiffness and lateral-torsional stability, Composite Structures, 132 (2015) 265-289.

[21] A.H. Sheikh, New Concept to include shear deformation in a curved beam element, J. of Struc. Eng. 128(3) (2002) 406-410.

[22] N.R. Bauld, L.S. Tzeng, A Vlasov theory for fibre-reinforced beams with thin-walled open cross section, Int. J. of Sol. and Struc. 20(3) (1984) 277-97.

[23] A.H. Sheikh, O.T. Thomsen, An efficient beam element for the analysis of laminated composite beams, Compos. Sci. and Tech. 68(2008) 2273-2281.

[24] SP. Machado, VH. Cortinez, Non-linear model for stability of thin-walled composite beams with shear deformation, Thin-Walled Struct. 43(10) (2005) 1615-45.

[25] S.Y. Back, K.M. Will, Shear-flexible thin-walled element for composite I-beams, Eng. Struc. 30(5) (2007) 1447-1458.

[26] N.-I. Kim, D. K. Shin, M.-Y. Kim, Improved flexural-torsional stability analysis of thin-walled composite beam and exact stiffness matrix, I. J. of Mech. Sci. 49(2007) 950-969. 


\section{APPENDIX A}

The non-zero elements appearing in the upper triangle of the symmetric matrix $\left[C_{g}\right]$ (Eq. (18)) are presented in their explicit form as follows (applicable for I and box sections).

$C_{11}^{g P}=C_{22}^{g P}=A, C_{13}^{\mathrm{gP}}=-B \cos \alpha-A(q \sin \alpha+r \cos \alpha)$

$C_{23}^{g P}=-B \sin \alpha+A(q \cos \alpha-r \sin \alpha), C_{33}^{g P}=C+2 r B+A\left(q^{2}+r^{2}\right)$

Where $(A, B, D, F)=\int_{t}\left(1, n, n^{2}, n^{3}\right) d n$

\section{APPENDIX B}

The non-zero elements appeared in the upper triangle of the symmetric matrix $\left[F_{g}^{P}\right]$ and $\left[F_{g}^{M}\right]$ (Eq. (18)) are presented in their explicit form as follows (applicable for I section, Fig. $3(\mathrm{a}))$.

$$
\begin{aligned}
& F_{11}^{g P}=F_{22}^{g}=b_{1} A_{1}+b_{2} A_{2}+d A_{3}, F_{13}^{g P}=-b_{1}\left(A_{1} d / 2+B_{1}\right)+b_{2}\left(A_{2} d / 2+B_{2}\right), F_{23}^{g P}=-B_{3} d \\
& F_{33}^{g P}=b_{1}^{3} A_{1} / 12+b_{1}\left(0.25 A_{1} d^{2}+B_{1} d+D_{1}\right)+b_{2}^{3} A_{2} / 12+b_{2}\left(0.25 A_{2} d^{2}+B_{2} d+D_{2}\right)+A_{3} d^{3} / 12+D_{3} d
\end{aligned}
$$

and

$$
\begin{aligned}
F_{11}^{g M}= & F_{22}^{g M}=b_{1}\left(0.5 A_{1} d+B_{1}\right)-b_{2}\left(0.5 A_{2} d+B_{2}\right), \\
F_{13}^{g M}= & -b_{1}\left(0.25 A_{1} d^{2}+B_{1} d+D_{1}\right)-b_{2}\left(0.25 A_{2} d^{2}+B_{2} d+D_{2}\right)-A_{3} d^{3} / 12, \\
F_{33}^{g M}= & b_{1}\left(b_{1}^{2} d A_{1}+2 b_{1}^{2} B_{1}+3 d^{3} A_{1}+18 d^{2} B_{1}+36 d D_{1} / 2+24 F_{1}\right) / 24 \\
& -b_{2}\left(b_{2}^{2} d A_{2}+2 b_{2}^{2} B_{2}+3 d^{3} A_{2}+18 d^{2} B_{2}+36 d D_{2} / 2+24 F_{2}\right) / 24
\end{aligned}
$$

The non-zero elements appeared in the upper triangle of the symmetric matrix $\left[F_{g}^{P}\right]$ and $\left[F_{g}^{M}\right]$ (Eq. (18)) are presented in their explicit form as follows (applicable for box section, Fig. 3(b)).

$$
\begin{aligned}
F_{11}^{g P}= & F_{22}^{g P}=b\left(A_{1}+A_{2}\right)+d\left(A_{3}+A_{4}\right), F_{13}^{g P}=b d\left(A_{2}-A_{1}\right) / 2-b\left(B_{2}-B_{1}\right), \\
F_{23}^{g P}= & b d\left(A_{4}-A_{3}\right) / 2+d\left(B_{4}-B_{3}\right), \\
F_{33}^{g P}= & b^{3}\left(A_{1}+A_{2}\right) / 12+b d^{2}\left(A_{1}+A_{2}\right) / 4+b^{2} d\left(A_{3}+A_{4}\right) / 4+b d\left(B_{1}+B_{2}+B_{3}+B_{4}\right) \\
& +b\left(C_{1}+C_{2}\right)+d^{3}\left(A_{3}+A_{4}\right) / 12+d\left(C_{3}+C_{4}\right) \\
\text { and } & \\
F_{11}^{g M}= & F_{22}^{g M}=b d\left(A_{1}-A_{2}\right) / 2+b\left(B_{1}-B_{2}\right), \\
F_{13}^{g M}= & -b d^{2}\left(A_{1}+A_{2}\right) / 4-b d\left(B_{1}+B_{2}\right)-b\left(D_{1}+D_{2}\right)+d^{3}\left(A_{3}+A_{4}\right) / 12, \\
F_{33}^{g M}= & b^{3} d\left(A_{1}-A_{2}\right) / 24+b^{3}\left(B_{1}-B_{2}\right) / 12+b d^{3}\left(A_{1}-A_{2}\right) / 8+3 b d^{2}\left(B_{1}-B_{2}\right) / 4 \\
& +3 b d\left(D_{1}-D_{2}\right) / 2+b\left(F_{1}-F_{2}\right)
\end{aligned}
$$

